\title{
The effectiveness of hypnosis for pain relief: A systematic review and meta-analysis of 85 controlled experimental trials
}

\author{
Trevor Thompson ${ }^{a}$, Devin B. Terhune ${ }^{b}$, Charlotte Oramª, Joseph Sharangparni ${ }^{a}$, Rommana \\ Roufa, Marco Solmic, Nicola Veronese ${ }^{d}$, Brendon Stubbse ${ }^{e}$
}

\begin{abstract}
aFaculty of Education and Health, University of Greenwich, London SE9 2UG, UK
bDepartment of Psychology, Goldsmiths, University of London, London, UK

'Department of Neuroscience, University of Padova, Padova, Italy

dNational Research Council, Neurosciences Department, Aging Branch, Padova, Italy

ePhysiotherapy Department, South London and Maudsley NHS Foundation Trust, London SE5 8AZ, UK

fDepartment of Psychological Medicine, King's College, De Crespigny Park, London SE5 8AF, UK
\end{abstract}

Corresponding Author:

Trevor Thompson, t.thompson@gre.ac.uk, +4420 83319632

Number of manuscript pages: 29

Number of figures: 3

Number of tables: 2

Online supplementary material: 2 (search strings and study validity ratings)

Word count (exc. abstract, references, tables): 4803

\section{Declaration of interest}

Declarations of interest: none 
HYPNOSIS AND PAIN

\section{ABSTRACT}

The current meta-analysis aimed to quantify the effectiveness of hypnosis for reducing pain and identify factors that influence efficacy. Six major databases were systematically searched for trials comparing hypnotic inductions with nointervention control conditions on pain ratings, threshold and tolerance using experimentally-evoked pain models in healthy participants. Eighty-five eligible studies (primarily crossover trials) were identified, consisting of 3632 participants (hypnosis $n=2892$, control $n=2646$ ). Random effects meta-analysis found analgesic effects of hypnosis for all pain outcomes ( $\left.g=0.54-0.76, p^{\prime} s<.001\right)$. Efficacy was strongly influenced by hypnotic suggestibility and use of direct analgesic suggestion. Specifically, optimal pain relief was obtained for hypnosis with direct analgesic suggestion administered to high and medium suggestibles, who respectively demonstrated $42 \%(p<.001)$ and $29 \%(p<.001)$ clinically meaningful reductions in pain. Minimal benefits were found for low suggestibles. These findings suggest that hypnotic intervention can deliver meaningful pain relief for most people and therefore may be an effective and safe alternative to pharmaceutical intervention. High quality clinical data is, however, needed to establish generalisability in chronic pain populations.

Keywords: pain; hypnosis; analgesia; review; meta-analysis; suggestion 
HYPNOSIS AND PAIN

\section{INTRODUCTION}

Pain affects up to 1.5 billion adults worldwide (Yaqub, 2015) and has a substantial negative impact on quality of life. In addition to becoming one of the leading causes of years lived with disability (GBD Causes of Death Collaborators, 2017), pain also incurs a massive economic burden. Pain-related health care and lost productivity incur annual costs of up to $\$ 635$ billion in the US alone (Gaskin and Richard, 2012), greater than that of heart disease, cancer or diabetes. Increasing concern over the side effects, addictive properties and costs of opioid medication has led to an urgent need to identify non-pharmacological interventions for pain that are effective, safe, and inexpensive.

One popular psychological intervention for pain management is hypnosis, which typically involves relaxation, focused attention and targeted verbal suggestion to alter perceptual experience and behaviour (Jensen and Patterson, 2014). Hypnosis is easily administered, has few or no side effects, and is inexpensive if delivered in a pre-recorded format (e.g., audio recording) that does not require the presence of a practitioner (Jensen et al., 2015). Recent research has indicated that hypnotic suggestion produces altered activity in key regions of the brain involved in pain regulation, including the anterior cingulate, prefrontal and insular cortices (Del Casale et al., 2015), and this could provide a basis for possible analgesic effects. Exaggerated claims of hypnotic analgesia have, however, created scepticism over its efficacy (Larkin, 1999), and a rigorous evaluation of controlled trials is needed to properly evaluate and quantify its effectiveness for reducing pain.

A recent meta-analysis of 14 trials of people with chronic pain (Adachi et al., 2014) concluded that hypnosis was effective for managing pain. However, this conclusion was based primarily on a subset of 4 studies comparing hypnosis with standard care $\left(d=.60, \mathrm{Cl}_{95}[0.03,1.17]\right)$ that was largely unreplicated in other subset comparisons. Individual study findings were inconsistent, probably resulting from variation in pain conditions, control comparisons (e.g. treatment-as-usual, no intervention) and hypnotic suggestibility of study samples, and thus this meta-analysis provides an 
unclear overall picture of the analgesic benefits of hypnosis. Other reviews have indicated beneficial effects of hypnosis on labour pain (Madden et al., 2016), and fibromyalgia (Bernardy et al., 2011), but have all concluded that supporting clinical evidence is of low methodological quality.

The effect of hypnosis on pain has also been examined using experimental paradigms to provide a level of methodological control difficult to achieve in clinical settings. A meta-analysis of 18 studies that included 12 experimental and 6 clinical trials (Montgomery et al., 2000) found significant moderate analgesic effects of hypnosis ( $d=.67)$. While this represents an important finding, several important limitations driven primarily by a lack of available data should be noted. First, determining the level of meaningful analgesia from hypnosis is difficult given the absence of a metric on which meaningful clinical change can be mapped (e.g. 0-10 numerical ratings). Second, estimates of hypnotic analgesia were complicated by considerable heterogeneity in control comparators. Third, factors such as hypnotic suggestibility and the use of direct analgesic suggestion that may be critical to treatment success (Patterson and Jensen, 2003) could not be adequately assessed. A large number of experimental studies have been published since this meta-analysis from almost 20 years ago, thereby providing a new opportunity for more reliable estimates of the effectiveness of hypnosis for pain reduction and to assess potential moderating factors.

To fill the gap in current knowledge regarding the efficacy of hypnosis for pain, we conducted a meta-analysis comparing hypnotic interventions with no-treatment control in studies using experimental pain models in healthy participants. Specific aims were to obtain precise estimates of: (1) the magnitude of hypnotic analgesia on standardized and unstandardized scales (e.g. 0-10 ratings); and (2) the degree to which intervention effectiveness is dependent upon both hypnotic suggestibility and the inclusion of direct suggestions of pain relief. 
HYPNOSIS AND PAIN

\section{METHOD}

This systematic review was conducted in accordance with the PRISMA-P 2015 statement for systematic review and meta-analysis protocols (Moher et al., 2015). An a priori but unpublished protocol was followed (available from the authors upon request).

\subsection{Eligibility Criteria}

Inclusion criteria were: (1) a hypnotic induction; (2) a non-hypnosis control condition with no active intervention; (3) an experimental pain stimulus administered to healthy participants; and (4) a quantitative assessment of pain. Although there is no established consensus for a definition of a hypnotic induction (Terhune and Cardeña, 2016), we used the conceptualisation by Jensen and Patterson (2014) of suggestions offered to another person to alter perceptual experience and voluntary action that typically involves relaxation, focused attention and/or imagery. Exclusion criteria were: (1) hypnosis induced by a pharmacological agent (e.g. ketamine); or (2) coadministration of hypnosis with other intervention(s).

\subsection{Search Strategy}

PubMed, EMBASE, PsycINFO, CINAHL, CENTRAL and Web of Science databases were searched independently by two reviewers (RR, JS) for potentially eligible studies indexed from database inception until $21^{\text {st }}$ May, 2018.

The search string consisted of three elements related to hypnosis AND pain AND experimental noxious stimuli (see Appendix S1). Specific free text words chosen for experimental pain methods were derived from Gracely (2005) and our previous meta-analyses (Thompson et al., 2017a; Thompson et al., 2017b). Searches were applied to all database fields where possible, or title/abstract/keywords where this restriction was imposed by the database. Results were limited a posteriori to "human studies' and searches were augmented through manual searches of reference lists of included articles and reviews. 
HYPNOSIS AND PAIN

\subsection{Study selection}

Titles and abstracts of articles returned by initial searches were independently screened by two reviewers (RR, JS) who rejected articles not meeting eligibility criteria. The full-text of remaining articles was independently examined by the same reviewers to reach a final list of articles. Disagreements at either screening stage were resolved through discussion with a third reviewer (TT). When an eligible article provided insufficient data for inclusion, corresponding authors were contacted up to 3 times over an 8-week period to request additional data. Of 20 author groups contacted, 6 (30\%) provided data sufficient to permit study inclusion (see acknowledgements section).

\subsection{Pain outcomes}

Outcome variables were: (1) self-reported pain ratings (e.g. 0-10 rating scale), (2) pain tolerance and (3) pain threshold. Pain threshold is the point at which pain is first detected and tolerance is the point at which pain can no longer be endured, with both measures typically quantified as stimulus intensity (e.g. temperature) or exposure time.

Pain ratings were included to provide a clinically meaningful measure of pain, with threshold and tolerance included as they represent behavioural responses to minimal and maximal pain respectively.

\subsection{Study quality}

Two raters (RR, JS) independently rated each study for methodological quality on a 15 -item validity scale assessing methodological rigour, selection and reporting bias (Table S1). Items were based on Cochrane criteria and PRISMA recommendations, and were adapted from Thompson et al. (2017a) for the current review.

\subsection{Data Extraction}

Extraction and coding of study data were performed by three authors (CO, RR, JS) on a standardized template (Thompson et al., 2017a), with all data entry checked by 
another reviewer (TT). The following data were extracted: (1) pain outcomes; (2) sample characteristics: age, gender, hypnotic suggestibility; (3) study characteristics: location, design, pain induction method; (4) hypnotic induction: method (e.g. Stanford procedure), format (e.g. verbal, virtual reality), direct suggestions of analgesia (present, absent), number/duration of sessions, control condition (nothing, placebo). For pain outcomes, when a study did not report $M s$ and SDs, effect sizes were calculated from any other statistics that allowed their computation based on standardised formulae (Cooper et al., 2009).

When a study provided data for multiple effect sizes (e.g. across different time points), all such data were extracted. In addition, the following extraction decisions were made: (1) for a few studies that did not report Ms/SDs but did report significance thresholds (e.g. $p<.01$ ), we conservatively rounded these to absolute $p$ values (e.g. $p=.01$ ) to compute effect size; (2) for a few studies that reported use of hyperalgesic (pain increasing) and analgesic suggestions across different hypnotic conditions, only analgesic data were extracted; (3) data from a few studies ( $k=3)$ that used control conditions involving reading, relaxation or a simple cognitive task were included, as although not entirely inactive, these were considered unlikely to have substantial analgesic effects; (4) for a few studies $(k=5)$ that collected pain ratings using a tolerance model (where stimulus intensity/exposure time can potentially vary across groups), pain outcome data were included. This was a conservative strategy, as all studies reported longer exposure times for hypnosis, so pain ratings in this condition would not be expected to be reduced due to the use of a tolerance model. For (1), (3) and (4), sensitivity analyses were conducted to examine their impact on effect size.

\subsection{Hypnotic suggestibility}

Hypnotic suggestibility is the degree of responsiveness to suggestions made within a hypnotic induction. Scoring is typically based on the aggregation of behavioural responses to a series of individual suggestions (e.g. whether suggestions of heaviness or tiredness in the arm produce lowering of the hand by 6 inches or more) 
(Weitzenhoffer and Hilgard, 1962). Study samples were classified as low, medium or high in hypnotic suggestibility if scores on standardised measures fell within the following ranges: (a) Harvard Group Scale of Hypnotic Suggestibility:Form A (HGSHS:A) and Stanford Hypnotic Suggestibility Scale (SHSS) forms A and C: low (04), medium (5-7), high (8-12) (Shor and Orne, 1963; Weitzenhoffer and Hilgard, 1962); (b) Carleton University Responsiveness to Suggestion Scale: Objective dimension (CURSS:O): low (0-2), medium (3-4), high (5-7) (Spanos et al., 1983b); and (c) Stanford Hypnotic Arm Levitation Induction and Test (SHALIT): low (0-3), medium (4-7), high (8-12) (Hilgard et al., 1979).

Classifications were made using two different methods. First, a study sample was classified as low, medium or high suggestibility if the reported study range fell within the above normative boundaries $(k=40)$. Second, as sometimes only mean scores were reported or ranges did not precisely match normative ranges, we used an alternative, less stringent classification to maximise study inclusion ( $k=67)$ for moderation analysis. Specifically, we made additional classifications when (a) the mean suggestibility score fell within normative boundaries (and range was not reported), or (b) reported study ranges closely approximated normative guidelines (e.g. when 0-5, rather than 0-4, was reported for the Stanford scale). We employed the less stringent classification in moderation analysis, but performed sensitivity analysis to evaluate the impact of this decision.

\subsection{Effect size}

The standardized mean difference (SMD) for hypnosis vs. control was computed with Hedges' $g$ formula (Cooper et al., 2009), where $0.20,0.50$ and 0.80 can be broadly translated as small, medium and large effects (Cohen, 1988). SMDs for all studies were computed using original (unadjusted) standard deviations, but effect size variance was computed dependent upon study design (Morris and DeShon, 2002). Effect sizes were coded so that positive values indicated beneficial effects of hypnosis (i.e. a decrease in pain ratings or an increase in threshold/tolerance). 


\subsection{Meta-analysis}

A random-effects model was used as heterogeneity in effect size due to variation in study methodology is likely. As studies typically report multiple effect size data (e.g. from the same subjects across multiple time points), we used a robust variance estimation (RVE) method (Hedges et al., 2010) to account for within-study dependency of effect sizes. In RVE, individual weights are based on the true common correlation of within-study effect sizes. Although this value is usually unknown, simulation studies have shown that different correlations tend to have little impact on results (Tanner-Smith and Tipton, 2014; Hedges et al., 2010). We used $r=0.65$ as our estimated correlation as this approximated that typically reported by studies employing repeated testing, but conducted sensitivity analysis using lower $(r=.40)$ and higher $(r=.90)$ correlations to examine the effect on parameter estimates. RVE meta-analysis estimates are most reliable when 10 or more studies are available (Tanner-Smith and Tipton, 2014). A few studies collected pain ratings on scales other than 0-10 (e.g. 0-20), and these were transformed to a 0-10 scale.

\subsection{Meta-regression}

RVE meta-regression analyses were performed to identify potential sources of heterogeneity size if moderate or greater inconsistency was found, as indicated by $\mathrm{I}^{2}>50 \%$ (Higgins et al., 2003) and 40 or more studies were available (Tanner-Smith and Tipton, 2014).

Primary moderators were: (1) hypnotic suggestibility (low/medium/high), and (2) direct analgesic suggestion (present/absent), with the hypothesis that hypnosis would produce greater analgesia when participants were higher in hypnotic suggestibility and direct suggestions of pain relief were present.

Secondary moderators were examined to provide preliminary data on any moderating influence of hypnosis method, format (audio recording/live), comparison group (control/placebo), study age, gender composition and pain induction method. Where the endorsement of important study validity criteria varied across studies, 
HYPNOSIS AND PAIN

the influence of these criteria as potential moderators of effect size was also assessed.

\subsection{Publication bias}

To assess potential publication bias, funnel plots of average study effect sizes against standard errors were examined for asymmetry resulting from a relative lack of small studies with small effect sizes (i.e. those most likely to be non-significant and remain unpublished). Asymmetry was also tested statistically with Egger's bias test (Egger et al., 1997) with $p<.05$ indicating asymmetry. If evidence of asymmetry was present, a revised effect size was computed using the trim and fill method (Duval and Tweedie, 2000).

All analyses were performed using the robumeta (Fisher and Tipton, 2014) and metafor (Viechtbauer, 2010) packages in R (R Core Team, 2017).

\section{RESULTS}

\subsection{Study inclusion}

An initial pool of 4,801 unique studies were identified through database searches, with 14 additional records acquired through manual searching of reference lists. Screening of titles/abstracts identified 229 potentially eligible articles, with full-text review resulting in a final list of 85 eligible studies (see Figure 1). Key characteristics of these studies are presented in Table 1.

\subsection{Participant characteristics}

The 85 studies provided data for 3,632 participants (hypnosis $n=2,892$, control $n=$ 2,646 , with crossover trials primarily used). Mean study age (reported by $k=28$ of 85 studies) was 24.6 years $(S D=4.5)$ for hypnosis and 25.4 years $(S D=4.4)$ for controls. 
HYPNOSIS AND PAIN

Mean gender composition $(k=62)$ was $63.5 \%$ female $(S D=22.4)$ for hypnosis and $63.1 \%$ female $(S D=23.8)$ for controls.

\subsection{Study characteristics}

Study designs used were crossover $(k=61)$, pre-post control $(k=22)$ and parallel groups ( $k=2)$. Study locations were USA $(k=32)$, Italy $(k=16)$, Canada $(k=15)$, Germany $(k=4)$, UK $(k=3)$, France $(k=3)$, Belgium $(k=3)$, Denmark $(k=2)$, Israel $(k=2)$, Netherlands $(k=1)$, Australia $(k=1)$, New Zealand $(k=1)$, Romania $(k=1)$ and Switzerland $(k=1)$.

\subsection{Pain assessment and induction}

Different pain assessment $(k s$ : intensity ratings $=66$, affective ratings $=24$, tolerance $=18$, threshold $=16)$ and pain induction ( $k s$ : cold $=23$, electric $=22$, pressure $=19$, heat $=16$, ischemic $=5$, laser $=2$ ) methods were used, with multiple assessment and induction methods within a single study sometimes employed. Noxious stimuli were most commonly applied to the hand $(k=62)$ or forearm/upper $\operatorname{arm}(k=12)$.

\subsection{Hypnotic induction and suggestibility}

Details of hypnotic induction procedures are provided in Table 1, which we broadly categorised as standard/typical hypnotic procedures $(k=55)$ and standardized (e.g. HGSHS/SHSS) inductions ( $k=30$ ) (both procedures typically include combinations of eye fixation, progressive relaxation and suggestions of drowsiness). Direct analgesic suggestions (e.g. 'you cannot feel pain because the glove you are wearing prevents you from feeling it') were present $(k=72)$ and/or absent $(k=37)$ and hypnosis was delivered in several formats ( $k$ : live=68, recorded audio=19, virtual media=3). Comparison conditions consisted of an inactive control $(k=83)$ and/or a placebo condition $(k=8)$ such as a sham analgesic spray.

Hypnotic suggestibility was assessed in 78 studies primarily using the SHSS ( $k=35$; form $C=28$, form $A=7)$, HGSHS:A ( $k=23)$, CURSS:O $(k=19)$, SHALIT $(k=2)$ and/or WSGC 
HYPNOSIS AND PAIN

$(k=2)$ tests. Most studies used a single session of hypnosis $(k=74)$, with a small subset using two $(k=10)$ or three sessions $(k=1)$ with sessions usually lasting 15-30 mins.

\subsection{Study validity criteria}

Study ratings for each validity criteria are shown in Appendix S2. Although most study criteria were well met, several criteria were not. Perhaps most importantly, only $42 \%$ of studies explicitly reported random allocation/counterbalancing. More specifically, 18/24 (75\%) parallel/pre-post control designs reported random group allocation, and only $18 / 61$ (30\%) crossover studies counterbalanced/randomised presentation order, with control procedures typically occurring first. As this could potentially result in bias from habituation or sensitisation to repeated pain stimulation, the impact of randomisation vs. non-randomisation on effect size was examined in moderation analysis. Only a few studies screened participants for preexisting pain (18\%) or gave details on use of pain medication (25\%), although these would seem less likely to present serious threats to overall conclusions given the primary use of crossover designs.

\subsection{Rater agreement}

For study selection, good rater agreement was shown at the full-text review stage (95\% agreement, kappa $=.80)$, with initial discrepancies primarily due to uncertainty over control group eligibility. For ratings of validity criteria, acceptable agreement was demonstrated for the majority of the individual items (agreement=77-99\%; kappa $=0.45-0.92$ ) with agreement lowest for adequacy of control group description (77\%) and recruitment procedures (83\%). In all cases of disagreement, $100 \%$ consensus was reached after discussion with a third reviewer (TT).

\subsection{Outliers}

Studentized residuals $>3.3$ from initial meta-analysis (Viechtbauer and Cheung, 2010) suggested one potential outlier for tolerance (Casiglia et al., 2007), one for pain affect (Price and Barber, 1987) and two for pain intensity (Faymonville et al., 2003; Crawford et al., 1993). Although no obvious reason for these outlying values could 
HYPNOSIS AND PAIN

be identified from further scrutiny of these papers, these cases were conservatively removed to prevent potential distortion of results (as these were all high positive values, removal resulted in marginally reduced, rather than inflated, effect sizes).

\subsection{Meta-analysis}

\subsubsection{Pain ratings: Intensity}

Meta-analysis of 64 studies (205 effect sizes) of pain intensity across 3,039 participants (hypnosis $n=2,366$, control $n=2,168$ ), found hypnosis to result in lower overall pain intensity, $S M D=0.74, \mathrm{Cl}_{95}[0.63,0.84], p<.001$ (Figure 2), classifiable as a large effect (Cohen, 1988). Positive effect sizes were found in all but one study, but with high inconsistency in magnitude $\left(I^{2}=75 \%\right)$.

Analysis of 52 studies which provided raw, unstandardized 0-10 ratings were consistent with these results (Mean Difference=1.49, $\mathrm{Cl}_{95}[1.21,1.78], p<.001$ ). A decrease from 5.5 to 4.0 points was observed with hypnosis, a reduction of around $27 \%$ or 1.5 points.

\subsubsection{Pain ratings: Affect}

Meta-analysis of 23 studies (103 effect sizes) of 751 participants (hypnosis $n=665$, control $n=587$ ) revealed similarly lower affective pain ratings for hypnosis, $S M D=0.76, \mathrm{Cl}_{95}[0.53,0.99], p<.001$. High inconsistency in effect size was observed $\left(I^{2}=78 \%\right)$, although positive effect sizes were observed for all 23 studies. Analysis of unstandardized 0-10 pain affect ratings from 18 studies indicated a mean reduction of 1.53 points, $\mathrm{Cl}_{95}[1.14,1.93], p<.001$, for hypnosis.

\subsubsection{Pain tolerance}

Meta-analysis of 17 studies (33 effect sizes) of 696 participants (hypnosis $n=536$, control $n=470$ ) indicated higher tolerance (i.e. reduced pain) for hypnosis, $S M D=0.54, \mathrm{Cl}_{95}[0.38,0.70], p<.001$. Positive effects were indicated in all studies, but with moderate inconsistency in effect size $\left(I^{2}=56 \%\right)$. 
HYPNOSIS AND PAIN

\subsubsection{Pain threshold}

Meta-analysis of 16 studies (64 effect sizes) of 415 participants (hypnosis $n=382$, control $n=380$ ) found higher pain threshold (i.e. reduced pain) for hypnosis, $S M D=0.66, \mathrm{Cl}_{95}[0.38,0.70], p<.001$. Positive effects were found for all studies, but with high inconsistency $\left(I^{2}=78 \%\right)$.

\subsection{Publication bias}

Funnel plots and Egger's test suggested asymmetry in pain intensity $(z=2.39, p=.017)$, tolerance $(z=2.30, p=.022)$ and threshold $(z=2.06, p=.039)$, that was consistent with possible publication bias. Trim and fill estimates produced slight reductions in effect sizes for intensity $(\triangle S M D=-.06$; Figure 3$)$, tolerance $(\triangle S M D=-.06)$ and threshold $(\triangle \mathrm{SMD}=-.04)$.

\subsection{Meta-regression}

Meta-regression was performed for pain intensity only as study numbers $(k=64)$ were considerably higher than other pain outcomes $(k s=16-23)$ and thus provide more reliable parameter estimates.

\subsubsection{Primary moderators}

Analgesic suggestion (yes, no) and hypnotic suggestibility (low, medium, high) were entered simultaneously as dummy-coded moderators, with no analgesic suggestion and low suggestibility coded as reference levels. Both variables were well represented by studies across their different levels (hypnotic suggestibility: low=31, medium=15, and high=43 studies; analgesic suggestion: yes=48, no=24 studies).

Meta-regression parameter estimates are shown in Table 2 for unstandardized (010) ratings and indicate greater pain relief for increasing suggestibility (+0.64 for medium, +1.34 points for high) and inclusion of a direct analgesic suggestion (+0.94 points). Solving the regression equation at different predictor values revealed that relative to control pain intensity ratings of 5.5 , hypnosis with direct analgesic 
HYPNOSIS AND PAIN

suggestion decreased pain by: 2.30 points $\left(\mathrm{Cl}_{95}[1.82,2.80], p<.001\right)$ in high suggestibles (42\% reduction), 1.60 points $\left(\mathrm{Cl}_{95}[1.23,1.99], p<.001\right)$ in medium suggestibles ( $29 \%$ reduction), and 0.97 points $\left(\mathrm{Cl}_{95}[0.61,1.32], p<.001\right)$ for low suggestibles ( $17 \%$ reduction).

Hypnosis with no direct analgesic suggestion decreased pain ratings by: 1.36 points $\left(\mathrm{Cl}_{95}[0.48,2.28], p=.004\right)$ in high suggestibles (25\% reduction), 0.67 points ( $\mathrm{Cl}_{95}[0.10$, 1.23], $p=.025)$ in medium suggestibles ( $12 \%$ reduction), and 0.03 points ( $\mathrm{Cl}_{95}[-0.65$, 0.59 ], $p=.931$ ) in low suggestibles ( $0.5 \%$ reduction), with the latter result not significant.

\subsubsection{Secondary moderators}

Separate meta-regression was performed for the following moderators after removing levels of any variable with low $(<5)$ study numbers: delivery format (audio recording, live), hypnotic induction method (standard procedure, standardized induction), comparison (control, placebo), pain induction (heat, electric, pressure, cold), age and study gender composition. We also examined whether randomisation vs. non-randomisation influenced effect size (Section 3.6). Results indicated hypnotic analgesia was marginally lower $(\triangle S M D=-.01)$ for studies reporting randomization (primarily of presentation order) relative to those that did not, but this was not significant $(p=.90)$. No secondary moderators were significant ( $p s=.22-.85)$.

\subsection{Sensitivity analysis}

We re-ran analyses using alternative correlations of effect sizes (section 2.9), using more stringent hypnotic suggestibility classifications (section 2.7), and with extraction decisions specified in Section 2.6, but found no substantive changes in parameter estimates. 
HYPNOSIS AND PAIN

\section{DISCUSSION}

The effectiveness of hypnosis for reducing pain was supported by meta-analysis of 85 controlled experimental trials totalling 3,632 participants. Key findings were: (1) hypnosis produced moderate to large overall analgesia for all pain outcomes; (2) hypnotic suggestibility and the inclusion of a direct analgesic suggestion are important determinants of intervention effectiveness; and (3) possible publication bias was identified, but had minimal impact on effect sizes.

\subsection{Magnitude of pain relief}

Hypnosis with analgesic suggestion produced a $42 \%$ reduction in pain intensity for those with high hypnotic suggestibility and a $29 \%$ reduction for those with medium hypnotic suggestibility. This is broadly supportive of a meaningful level of analgesia based on established guidelines for clinically important change, where $a \geq 30 \%$ reduction in pain typically represents 'much improved' (although $\geq 50 \%$ reductions are needed for 'very much improved')(Dworkin et al., 2008).

Importantly, pain relief approaching or exceeding 30\% was dependent upon (1) the inclusion of direct suggestion of pain relief, and (2) a target population of individuals high or medium in hypnotic suggestibility. Insofar as the majority of the general population (85-90\%) fall into the medium to high hypnotic suggestibility range (McConkey, 2012), these findings suggest that most individuals are able to experience meaningful analgesia from hypnosis provided direct analgesic suggestions are included. Hypnotic suggestibility has also been shown to influence efficacy of hypnosis in clinical care settings, although a meta-analysis of 10 studies by Montgomery et al. (2011) found relatively small moderating effects and questioned the usefulness of pre-assessing hypnotic suggestibility. However, Montgomery et al. (2011) examined a broad range of medical, dental and mental health conditions that included only 3 available pain studies, and thus further data is needed before conclusions on generalisability to clinical pain contexts can be made. 


\subsection{Previous findings}

Analgesic effects of hypnosis in experimental pain trials are consistent with a previous meta-analysis published almost 20 years ago (Montgomery et al., 2000). Due to a vastly increased number of experimental pain trials in the current ( 85 studies) compared to the original meta-analysis (12 studies), current findings were also able to provide precise estimates of analgesia on a more meaningful (0-10) metric. We were also able to identify hypnotic suggestibility and use of analgesic suggestion as important determinants of treatment efficacy, as has long been suspected (Patterson and Jensen, 2003). Beneficial effects of hypnosis on pain have also been supported in reviews of labour pain (Madden et al., 2016), fibromyalgia (Bernardy et al., 2011) and other pain conditions (Adachi et al., 2014), although these reviews acknowledge the low quality of methodological evidence.

\subsection{Implications}

The present analysis has several important implications. Hypnosis may be an effective intervention for pain that could be offered as a safe alternative to medication, especially where concerns exist for an individual over the effectiveness, addictive potential or side effects of drug treatment. If hypnosis could be administered as effectively at home (e.g., in the form of pre-recorded audio) as during live sessions with a practitioner, then this could also provide an inexpensive treatment option for pain. This would be of considerable potential benefit given that the costs of prescription opioid addiction alone are estimated at over $\$ 78$ billion annually in the US (Seth et al., 2018). However, while moderation analysis found no differences in analgesia between recorded audio and live hypnosis, suggesting the former may be similarly effective, we examined delivery format only as a secondary moderator. Furthermore, we did not perform an economic analysis, and so no claims of improved cost-effectiveness relative to opioids can therefore be made from the current study.

Hypnotic interventions should also include direct suggestions of analgesia and delivered to a high/medium hypnotic suggestibility target population to be most 
effective. As high/medium hypnotic suggestibility represents the majority of the population, this suggests treatment may be widely effective. Although the extent to which hypnotic suggestibility moderates treatment efficacy for clinical outcomes has yet to be firmly established (Montgomery et al., 2011), brief suggestibility screening (e.g., Morgan and Hilgard, 1978) may help identify therapeutic targets likely to demonstrate optimal benefits from hypnosis. In addition, some evidence indicates hypnotic suggestibility can be increased through training and practice (Patterson and Jensen, 2003), non-invasive brain stimulation (Dienes and Hutton, 2013; Coltheart et al., 2018), and pharmacological agents (Whalley and Brooks, 2009), and general engagement improved with the use of virtual reality formats (Thompson et al., 2011), which may help increase efficacy in those with low suggestibility.

\subsection{Mechanisms}

Although the precise analgesic mechanisms underpinning hypnosis have yet to be established, several explanations have been considered. Imaging studies reliably show hypnoanalgesic suggestion to alter activity in the anterior cingulate cortex, insular and prefrontal areas (Del Casale et al., 2015), possibly reflecting the role of these brain regions in mental relaxation, absorption and stimuli-awareness. As these areas also form a critical part of the pain neuromatrix, which plays an important part in pain modulation (Jensen and Patterson, 2014), this could provide a neural basis for hypnotic analgesia. The anterior cingulate and frontal regions may also differ across low and high suggestibles in both their structural properties and their activation in response to hypnotic induction (Jensen et al., 2017), which could account for the differential effectiveness of hypnosis across these groups.

Psychological models suggest that hypnotic induction produces an attentional shift away from external perceptual information which decreases monitoring of sensory cues and thus reduces pain (Jensen and Patterson, 2014). The fact that analgesia appears to be far more pronounced in those with high suggestibility is perhaps unsurprising, given that a greater responsivity to or willingness to engage with the 
HYPNOSIS AND PAIN

psychological components of an intervention would seem likely to enhance any therapeutic effects.

\subsection{Limitations}

The current findings have several important limitations. First, although evoked-pain models allow precise experimental control, chronic pain is often more sustained, diffuse and distressing, and this may threaten generalisability of the current findings to clinical pain (Arendt-Nielsen and Hoeck, 2011). Nevertheless, evidence from the current findings of meaningful pain reduction suggest a promising foundation for hypnosis as a clinical pain management technique. Second, relatively brief, one-off pain inductions were typically used, and the efficacy of hypnosis may decrease (or increase) over longer time periods. Third, reduced self-reported pain ratings might be partly attributable to undetected biases such as demand characteristics and response expectancies (Lynn et al., 2008). This concern may be partly mitigated by the analgesic effects of hypnosis for behavioural (threshold/tolerance) measures found here, and on 'objective' biomarkers such as altered brain activity in the pain matrix (Del Casale et al., 2015) and reduced medication requests in clinical settings (Lang et al., 2000; Montgomery et al., 2007) in previous studies. Fourth, the low mean study age $(M=24.5, S D=4.4)$ questions applicability of findings to older populations where non-pharmacological interventions have the potential to be most useful due to increased sensitivity to the adverse effects of medication (Thompson et al., 2017c). Finally, we are unable to comment on the relative efficacy of hypnosis compared to analgesic medication, and there appear to be few, if any, primary studies that have directly compared the two.

\subsection{Future studies}

Additional well-controlled research establishing whether the current findings generalise to clinical pain is critical for establishing the viability of hypnosis as an effective pain intervention. Although the role of hypnotic intervention in clinical pain settings is well researched, limited high quality data with numerous design biases prohibits reliable conclusions (Bernardy et al., 2011; Birnie et al., 2014; Landolt and 
Milling, 2011) and further well-controlled clinical studies are needed. In addition, the use of experimental models that produce hyperalgesic states (e.g. through capsaicin inflammation) and that mimic key pathological features of central sensitization in chronic pain but with strict experimental control (Chizh, 2007) are also likely to provide valuable insights.

\subsection{Conclusions}

This is the largest meta-analysis to date investigating the effectiveness of hypnosis as a technique for pain reduction. Evidence from 85 controlled studies provides convincing evidence that hypnosis produces substantive analgesia, with optimal pain relief delivered when direct analgesic suggestions are used in a target population of individuals high in suggestibility. Overall, the findings that hypnotic induction resulted in a reliable decrease in experimentally-induced pain suggest that hypnosis may represent a potentially effective and safe alternative or adjunct to pharmacological intervention for acute pain. Well-controlled studies of nonlaboratory pain are, however, essential to establish the efficacy of hypnosis for the treatment and management of clinical pain.

\section{ACKNOWLEDGEMENTS}

We are very grateful to Drs Casiglia, Croft, Facco, Milling, Santarcangelo and Sandrini for their helpful responses to data requests.

\section{FUNDING}

This research did not receive any specific grant from funding agencies in the public, commercial, or not-for-profit sectors. 
HYPNOSIS AND PAIN

\section{LIST OF FIGURE CAPTIONS}

Figure 1. PRISMA flowchart of study selection process.

Figure 2. Forest plot of Standardised Mean Differences (with 95\% confidence intervals) and study weights for 64 pain intensity studies.

Figure 3. Funnel plot of standardized mean differences ( $S M D s)$ from 64 pain intensity studies (filled circles) and 7 SMDs potentially missing due to publication bias imputed using the trim and fill method (empty circles).

\section{LIST OF TABLE CAPTIONS}

Table 1. Summary characteristics of included studies.

Table 2. Meta-regression estimates of unstandardized (0-10) pain intensity ratings and $95 \%$ confidence intervals $(\mathrm{Cl})$. 


\section{REFERENCES}

Adachi, T., Fujino, H., Nakae, A., Mashimo, T., \& Sasaki, J., 2014. A meta-analysis of hypnosis for chronic pain problems: A comparison between hypnosis, standard care, and other psychological interventions. Int J Clin Exp Hypn. 62(1), 1-28.

Arendt-Nielsen, L., \& Hoeck, H.C., 2011. Optimizing the early phase development of new analgesics by human pain biomarkers. Expert Rev Neurother. 11, 1631-1651.

Benhaiem, J.M., Attal, N., Chauvin, M., Brasseur, L., \& Bouhassira, D., 2001. Local and remote effects of hypnotic suggestions of analgesia. Pain. 89(2-3), 167-173.

Bernardy, K., Füber, N., Klose, P., \& Häuser, W., 2011. Efficacy of hypnosis/guided imagery in fibromyalgia syndrome--a systematic review and meta-analysis of controlled trials. BMC Musculoskelet Disord. 12, 1-11.

Bhatt, R.R. et al., 2017. The effect of hypnosis on pain and peripheral blood flow in sickle-cell disease: a pilot study. J Pain Res. 10, 1635-1644.

Birnie, K.A. et al., 2014. Systematic review and meta-analysis of distraction and hypnosis for needle-related pain and distress in children and adolescents. J Pediatr Psychol. 39(8), 783-808.

Braboszcz, C., Brandao-Farinelli, E., \& Vuilleumier, P., 2017. Hypnotic analgesia reduces brain responses to pain seen in others. Sci Rep. 7(1), 9778.

Casiglia, E. et al., 2017. Hypnotic Focused Analgesia Obtained Through Body Dysmorphism Prevents Both Pain and Its Cardiovascular Effects. Sleep \& Hypnosis. 19(4), 89-95.

Casiglia, E. et al., 2007. Hypnosis prevents the cardiovascular response to cold pressor test. Am J Clin Hypn. 49(4), 255-266.

Chizh, B.A., 2007. Low dose ketamine: a therapeutic and research tool to explore Nmethyl-D-aspartate (NMDA) receptor-mediated plasticity in pain pathways. J. Psychopharmacol. 21(3), 259-271.

Cohen, J., 1988. Statistical power analysis for the behavioral sciences. Lawrence Earlbaum Associates, Hillsdale, NJ

Coltheart, M. et al., 2018. Belief, delusion, hypnosis, and the right dorsolateral prefrontal cortex: A transcranial magnetic stimulation study. Cortex. 101, 234-248.

Cooper, H., Hedges, L., \& Valentine, J., 2009. Handbook of research synthesis and meta-analysis. Russell Sage Foundation, NY

Crawford, H.J., Gur, R.C., Skolnick, B., Gur, R.E., \& Benson, D.M., 1993. Effects of hypnosis on regional cerebral blood flow during ischemic pain with and without suggested hypnotic analgesia. Int J Psychophysiol. 15(3), 181-195.

Croft, R.J., Williams, J.D., Haenschel, C., \& Gruzelier, J.H., 2002. Pain perception, hypnosis and $40 \mathrm{~Hz}$ oscillations. Int J Psychophysiol. 46(2), 101-108.

Dahlgren, L.A., Kurtz, R.M., Strube, M.J., \& Malone, M.D., 1995. Differential effects of hypnotic suggestion on multiple dimensions of pain. J Pain Symptom Manage. 10(6), 464-470.

Danziger, N. et al., 1998. Different strategies of modulation can be operative during hypnotic analgesia: a neurophysiological study. Pain. 75(1), 85-92.

De Pascalis, V., Bellusci, A., Gallo, C., Magurano, M.R., \& Chen, A.C., 2004a. Painreduction strategies in hypnotic context and hypnosis: ERPs and SCRs during a secondary auditory task. Int J Clin Exp Hypn. 52(4), 343-363.

De Pascalis, V., Cacace, I., \& Massicolle, F., 2004b. Perception and modulation of pain 
in waking and hypnosis: functional significance of phase-ordered gamma oscillations. Pain. 112(1-2), 27-36.

De Pascalis, V., \& Carboni, G., 1997. P300 event-related-potential amplitudes and evoked cardiac responses during hypnotic alteration of somatosensory perception. Int J Neurosci. 92(3-4), 187-207.

De Pascalis, V., Magurano, M.R., \& Bellusci, A., 1999. Pain perception, somatosensory event-related potentials and skin conductance responses to painful stimuli in high, mid, and low hypnotizable subjects: effects of differential pain reduction strategies. Pain. 83(3), 499-508.

De Pascalis, V., Magurano, M.R., Bellusci, A., \& Chen, A.C., 2001. Somatosensory event-related potential and autonomic activity to varying pain reduction cognitive strategies in hypnosis. Clin Neurophysiol. 112(8), 1475-1485.

De Pascalis, V., \& Perrone, M., 1996. EEG asymmetry and heart rate during experience of hypnotic analgesia in high and low hypnotizables. Int J Psychophysiol. 21(2-3), 163-175.

De Pascalis, V., \& Scacchia, P., 2016. Hypnotizability and Placebo Analgesia in Waking and Hypnosis as Modulators of Auditory Startle Responses in Healthy Women: An ERP Study. PLoS ONE. 11(8), e0159135.

De Pascalis, V., Varriale, V., \& Cacace, I., 2015. Pain modulation in waking and hypnosis in women: event-related potentials and sources of cortical activity. PLoS ONE. 10(6), e0128474.

De Pascalis, V., Cacace, I., \& Massicolle, F., 2008. Focused analgesia in waking and hypnosis: Effects on pain, memory, and somatosensory event-related potentials. Pain. 134(1-2), 197-208.

DeBenedittis, G., Panerai, A.A., \& Villamira, M.A., 1989. Effects of hypnotic analgesia and hypnotizability on experimental ischemic pain. Int J Clin Exp Hypn. 37(1), 55-69.

Del Casale, A. et al., 2015. Hypnosis and pain perception: An Activation Likelihood Estimation (ALE) meta-analysis of functional neuroimaging studies. J Physiol Paris. 109(4-6), 165-172.

Derbyshire, S.W.G., Whalley, M.G., Seah, S.T.H., \& Oakley, D.A., 2017. Suggestions to Reduce Clinical Fibromyalgia Pain and Experimentally Induced Pain Produce Parallel Effects on Perceived Pain but Divergent Functional MRI-Based Brain Activity. Psychosom. Med. 79(2), 189-200.

Dienes, Z., \& Hutton, S., 2013. Understanding hypnosis metacognitively: rTMS applied to left DLPFC increases hypnotic suggestibility. Cortex. 49(2), 386-392.

Duval, S., \& Tweedie, R., 2000. Trim and fill: A simple funnel-plot-based method of testing and adjusting for publication bias in meta-analysis. Biometrics. 56(2), 455463.

Dworkin, R.H. et al., 2008. Interpreting the clinical importance of treatment outcomes in chronic pain clinical trials: IMMPACT recommendations. J Pain. 9(2), 105-121.

Egger, M., Davey Smith, G., Schneider, M., \& Minder, C., 1997. Bias in meta-analysis detected by a simple, graphical test. BMJ. 315(7109), 629-634.

Enea, V., Dafinoiu, I., Opriş, D., \& David, D., 2014. Effects of hypnotic analgesia and virtual reality on the reduction of experimental pain among high and low hypnotizables. Int J Clin Exp Hypn. 62(3), 360-377.

Evans, M.B., \& Paul, G.L., 1970. Effects of hypnotically suggested analgesia on 
physiological and subjective responses to cold stress. J Consult Clin Psychol. 35(3), 362-371.

Facco, E. et al., 2011. Effects of hypnotic focused analgesia on dental pain threshold. Int J Clin Exp Hypn. 59(4), 454-468.

Faymonville, M.E. et al., 2000. Neural mechanisms of antinociceptive effects of hypnosis. Anesthesiology. 92(5), 1257-1267.

Faymonville, M.E. et al., 2003. Increased cerebral functional connectivity underlying the antinociceptive effects of hypnosis. Cogn Brain Res. 17(2), 255-262.

Fidanza, F., Varanini, M., Ciaramella, A., Carli, G., \& Santarcangelo, E.L., 2017. Pain modulation as a function of hypnotizability: Diffuse noxious inhibitory control induced by cold pressor test vs explicit suggestions of analgesia. Physiology \& Behavior. 171, 135-141.

Fisher, Z., \& Tipton, E., 2014. robumeta: Robust variance meta-regression. R package version 1.3.

Fricton, J.R., \& Roth, P., 1985. The effects of direct and indirect hypnotic suggestions for analgesia in high and low susceptible subjects. Am J Clin Hypn. 27(4), 226-231.

Friederich, M. et al., 2001. Laser-evoked potentials to noxious stimulation during hypnotic analgesia and distraction of attention suggest different brain mechanisms of pain control. Psychophysiology. 38(5), 768-776.

Gaskin, D.J., \& Richard, P., 2012. The economic costs of pain in the United States. J Pain. 13(8), 715-724.

Collaborators, G.B.D.C.O.D., 2017. Global, regional, and national age-sex specific mortality for 264 causes of death, 1980-2016: a systematic analysis for the Global Burden of Disease Study 2016. Lancet. 390(10100), 1151-1210.

Goodin, B.R. et al., 2012. Experimental pain ratings and reactivity of cortisol and soluble tumor necrosis factor- $\alpha$ receptor II following a trial of hypnosis: results of a randomized controlled pilot study. Pain Med. 13(1), 29-44.

Gracely, R.H., 2005. Studies of pain in human subjects, in: R. Melzack \& P. Wall (Eds.), Textbook of pain (5th ed., pp. 267-289). London: Elsevier.

Green, S.A., 2010. Experimental pain in hypnosis research: Ischemic vs transcutaneous electrical nerve stimulation (TENS). Dissertation Abstracts International: Section B: The Sciences and Engineering. 71(4-B), 2685.

Greene, R.J., \& Reyher, J., 1972. Pain tolerance in hypnotic analgesic and imagination states. J. Abnorm. Psychol. 79(1), 29-38.

Hargadon, R., Bowers, K.S., \& Woody, E.Z., 1995. Does counterpain imagery mediate hypnotic analgesia? J. Abnorm. Psychol. 104(3), 508-516.

Hedges, L.V., Tipton, E., \& Johnson, M.C., 2010. Robust variance estimation in metaregression with dependent effect size estimates. Res Synth Methods. 1, 39-65.

Higgins, J.P., Thompson, S.G., Deeks, J.J., \& Altman, D.G., 2003. Measuring inconsistency in meta-analyses. BMJ. 327(7414), 557-560.

Hilgard, E.R., Crawford, H.J., \& Wert, A., 1979. The Stanford Hypnotic Arm Levitation Induction and Test (SHALIT): a six-minute hypnotic induction and measurement scale. Int J Clin Exp Hypn. 27(2), 111-124.

Hofbauer, R.K., Rainville, P., Duncan, G.H., \& Bushnell, M.C., 2001. Cortical representation of the sensory dimension of pain. J. Neurophysiol. 86(1), 402-411.

Jacobs, A.L., Kurtz, R.M., \& Strube, M.J., 1995. Hypnotic analgesia, expectancy effects, and choice of design: a reexamination. Int J Clin Exp Hypn. 43(1), 55-69. 
Jensen, M.P. et al., 2015. Mechanisms of hypnosis: toward the development of a biopsychosocial model. Int J Clin Exp Hypn. 63(1), 34-75.

Jensen, M.P. et al., 2017. New directions in hypnosis research: strategies for advancing the cognitive and clinical neuroscience of hypnosis. Neurosci Conscious. 3(1), 1-14.

Jensen, M.P., \& Patterson, D.R., 2014. Hypnotic approaches for chronic pain management: clinical implications of recent research findings. Am Psychol. 69(2), 167-177.

Karlin, R.A., Morgan, D., \& Goldstein, L., 1980. Hypnotic analgesia: A preliminary investigation of quantitated hemispheric electroencephalographic and attentional correlates. J. Abnorm. Psychol. 89(4), 591-594.

Kiernan, B.D., Dane, J.R., Phillips, L.H., \& Price, D.D., 1995. Hypnotic analgesia reduces $\mathrm{R}$-III nociceptive reflex: Further evidence concerning the multifactorial nature of hypnotic analgesia. Pain. 60(1), 39-47.

Kramer, S., Zims, R., Simang, M., Rüger, L., \& Irnich, D., 2014. Hypnotic relaxation results in elevated thresholds of sensory detection but not of pain detection. BMC Complement Altern Med. 14(1), 600-615.

Landolt, A.S., \& Milling, L.S., 2011. The efficacy of hypnosis as an intervention for labor and delivery pain: a comprehensive methodological review. Clin Psychol Rev. 31(6), 1022-1031.

Lang, E.V. et al., 2000. Adjunctive non-pharmacological analgesia for invasive medical procedures: a randomised trial. Lancet. 355(9214), 1486-1490.

Langlade, A., Jussiau, C., Lamonerie, L., Marret, E., \& Bonnet, F., 2002. Hypnosis increases heat detection and heat pain thresholds in healthy volunteers. Reg Anesth Pain Med. 27(1), 43-46.

Larkin, M., 1999. Hypnosis makes headway in the clinic. Lancet. 353(9150), 386.

Li, C.L. et al., 1975. Acupuncture and hypnosis: Effects on induced pain. Exp Neurol. 49(1, Pt 1), 272-280.

Lynn, S.J., Kirsch, I., \& Hallquist, M.N., 2008. Social cognitive theories of hypnosis, in: M. R. Nash \& A. J. Barnier (Eds.), The Oxford handbook of hypnosis: Theory, research and practice (pp. 111-140). Oxford: Oxford University Press.

Madden, K., Middleton, P., Cyna, A.M., Matthewson, M., \& Jones, L., 2016. Hypnosis for pain management during labour and childbirth. Cochrane Database Syst Rev. 5, CD009356.

Malone, M.D., Kurtz, R.M., \& Strube, M.J., 1989. The effects of hypnotic suggestion on pain report. Am J Clin Hypn. 31(4), 221-230.

Maurer, C., Santangelo, M., \& Claiborn, C.D., 1993. The effects of direct versus indirect hypnotic suggestion on pain in a cold pressor task. Int J Clin Exp Hypn. 41(4), 305-316.

McConkey, K.M., 2012. Generations and landscapes of hypnosis: Questions we've asked, questions we should ask, in: M. R. Nash \& A. J. Barnier (Eds.), The Oxford Handbook of Hypnosis (pp. 53-77). Oxford, UK: Oxford University Press.

Milling, L.S., 2009. Response expectancies: A psychological mechanism of suggested and placebo analgesia. Contemporary Hypnosis. 26(2), 93-110.

Milling, L.S., \& Breen, A., 2003. Mediation and moderation of hypnotic and cognitivebehavioural pain reduction. Contemporary Hypnosis. 20(2), 81-97.

Milling, L.S., Coursen, E.L., Shores, J.S., \& Waszkiewicz, J.A., 2010a. Imaginative 
suggestibility and hypnotizability: Deconstructing hypnotic suggestibility. Contemporary Hypnosis. 27(4), 233-256.

Milling, L.S., Coursen, E.L., Shores, J.S., \& Waszkiewicz, J.A., 2010b. The predictive utility of hypnotizability: The change in suggestibility produced by hypnosis. J Consult Clin Psychol. 78(1), 126-130.

Milling, L.S., Kirsch, I., Allen, G.J., \& Reutenauer, E.L., 2005. The Effects of Hypnotic and Nonhypnotic Imaginative Suggestion on Pain. Ann Behav Med. 29(2), 116-127.

Milling, L.S., Kirsch, I., Meunier, S.A., \& Levine, M.R., 2002. Hypnotic analgesia and stress inoculation training: Individual and combined effects in analog treatment of experimental pain. Cog. Ther. Res. 26(3), 355-371.

Milling, L.S., Shores, J.S., Coursen, E.L., Menario, D.J., \& Farris, C.D., 2007. Response expectancies, treatment credibility, and hypnotic suggestibility: Mediator and moderator effects in hypnotic and cognitive-behavioral pain interventions. Ann Behav Med. 33(2), 167-178.

Milling, L.S., Kirsch, I., \& Burgess, C.A., 1999. Brief modification of suggestibility and hypnotic analgesia: too good to be true. Int J Clin Exp Hypn. 47(2), 91-103.

Milling, L.S., Levine, M.R., \& Meunier, S.A., 2003. Hypnotic enhancement of cognitive-behavioral interventions for pain: an analogue treatment study. Health Psychol. 22(4), 406-413.

Moher, D. et al., 2015. Preferred reporting items for systematic review and metaanalysis protocols (PRISMA-P) 2015 statement. Syst Rev. 4(1), 1-9.

Montgomery, G.H. et al., 2007. A randomized clinical trial of a brief hypnosis intervention to control side effects in breast surgery patients. J. Natl. Cancer Inst. 99(17), 1304-1312.

Montgomery, G.H., Schnur, J.B., \& David, D., 2011. The impact of hypnotic suggestibility in clinical care settings. Int J Clin Exp Hypn. 59(3), 294-309.

Montgomery, G.H., DuHamel, K.N., \& Redd, W.H., 2000. A meta-analysis of hypnotically induced analgesia: How effective is hypnosis. Int J Clin Exp Hypn. 48(2), 138-153.

Morgan, A.H., \& Hilgard, J.R., 1978. The Stanford hypnotic clinical scale for adults. Am J Clin Hypn. 21, 134-147.

Morgan, A.H., Lezard, F., Prytulak, S., \& Hilgard, E.R., 1970. Augmenters, reducers, and their reaction to cold pressor pain in waking and suggested hypnotic analgesia. J Pers Soc Psychol. 16(1), 5-11.

Morris, S.B., \& DeShon, R.P., 2002. Combining effect size estimates in meta-analysis with repeated measures and independent-groups designs. Psychol Methods. 7(1), 105.

Patterson, D.R., Hoffman, H.G., Palacios, A.G., \& Jensen, M.J., 2006. Analgesic effects of posthypnotic suggestions and virtual reality distraction on thermal pain. J. Abnorm. Psychol. 115(4), 834-841.

Patterson, D.R., \& Jensen, M.P., 2003. Hypnosis and clinical pain. Psychol Bull. 129(4), 495-521.

Price, D.D., \& Barber, J., 1987. An analysis of factors that contribute to the efficacy of hypnotic analgesia. J. Abnorm. Psychol. 96(1), 46-51.

R Core Team., 2017. R: A language and environment for statistical computing. $R$ Foundation for Statistical Computing, Vienna, Austria

Rainville, P., Bao, Q.V., \& Chrétien, P., 2005. Pain-related emotions modulate 
experimental pain perception and autonomic responses. Pain. 118(3), 306-318.

Rainville, P., Carrier, B., Hofbauer, R.K., Bushnell, M.C., \& Duncan, G.H., 1999.

Dissociation of sensory and affective dimensions of pain using hypnotic modulation. Pain. 82(2), 159-171.

Rainville, P., Duncan, G.H., Price, D.D., Carrier, B., \& Bushnell, M.C., 1997. Pain affect encoded in human anterior cingulate but not somatosensory cortex. Science. 277(5328), 968-971.

Ray, W.J., Keil, A., Mikuteit, A., Bongartz, W., \& Elbert, T., 2002. High resolution EEG indicators of pain responses in relation to hypnotic susceptibility and suggestion. Bio. Psychol. 60(1), 17-36.

Röder, C.H., Michal, M., Overbeck, G., van de Ven, V.G., \& Linden, D.E., 2007. Pain response in depersonalization: a functional imaging study using hypnosis in healthy subjects. Psychother Psychosom. 76(2), 115-121.

Sandrini, G. et al., 2000. Effects of hypnosis on diffuse noxious inhibitory controls. Physiology \& Behavior. 69(3), 295-300.

Santarcangelo, E.L. et al., 2013. Cognitive modulation of psychophysical, respiratory and autonomic responses to cold pressor test. PLoS ONE. 8(10), e75023.

Seth, P., Scholl, L., Rudd, R.A., \& Bacon, S., 2018. Overdose Deaths Involving Opioids, Cocaine, and Psychostimulants - United States, 2015-2016. MMWR. 67(12), 349358.

Sharav, Y., \& Tal, M., 2004. Focused analgesia and generalized relaxation produce differential hypnotic analgesia in response to ascending stimulus intensity. Int J Psychophysiol. 52(2), 187-196.

Sharav, Y., \& Tal, M., 2006. Focused hypnotic analgesia: Local and remote effects. Pain. 124(3), 280-286.

Shor, R.E., \& Orne, E.C., 1963. Norms on the Harvard group scale of hypnotic susceptibility, form A. Int J Clin Exp Hypn. 11, 39-47.

Spanos, N.P., Gwynn, M.I., \& Stam, H.J., 1983a. Instructional demands and ratings of overt and hidden pain during hypnotic analgesia. J. Abnorm. Psychol. 92(4), 479488.

Spanos, N.P., \& Hewitt, E.C., 1980. The hidden observer in hypnotic analgesia: Discovery or experimental creation. J Pers Soc Psychol. 39(6), 1201-1214.

Spanos, N.P., \& Katsanis, J., 1989. Effects of instructional set on attributions of nonvolition during hypnotic and nonhypnotic analgesia. J Pers Soc Psychol. 56(2), 182-188.

Spanos, N.P., Kennedy, S.K., \& Gwynn, M.I., 1984. Moderating effects of contextual variables on the relationship between hypnotic susceptibility and suggested analgesia. J. Abnorm. Psychol. 93(3), 285-294.

Spanos, N.P., MacDonald, D.K., \& Gwynn, M.I., 1988. Instructional set and the relative efficacy of hypnotic and waking analgesia. Canadian Journal of Behavioural Science. 20(1), 64-72.

Spanos, N.P., Ollerhead, V.G., \& Gwynn, M.I., 1985. The effects of three instructional treatments on pain magnitude and pain tolerance: Implications for theories of hypnotic analgesia. Imagination, Cognition and Personality. 5(4), 321-337.

Spanos, N.P., Perlini, A.H., Patrick, L., Bell, S., \& Gwynn, M.I., 1990. The role of compliance in hypnotic and nonhypnotic analgesia. J Res Pers. 24(4), 433-453. Spanos, N.P., Voorneveld, P.W., \& Gwynn, M.I., 1986. The mediating effects of 
expectation on hypnotic and nonhypnotic pain reduction. Imagination, Cognition and Personality. 6(3), 231-245.

Spanos, N.P., Perlini, A.H., \& Robertson, L.A., 1989. Hypnosis, suggestion, and placebo in the reduction of experimental pain. J. Abnorm. Psychol. 98(3), 285-293.

Spanos, N.P. et al., 1983b. The Carleton University Responsiveness to Suggestion Scale: relationship with other measures of hypnotic susceptibility, expectancies, and absorption. Psychol Rep. 53(3 Pt 1), 723-734.

Stam, H.J., 1984. Hypnotic analgesia and the placebo effect: Controlling ischemic pain. PhD. Carleton University, Ottawa, Canada.

Stam, H.J., \& Spanos, N.P., 1980. Experimental designs, expectancy effects, and hypnotic analgesia. J. Abnorm. Psychol. 89(6), 751-762.

Stam, H.J., \& Spanos, N.P., 1987. Hypnotic analgesia, placebo analgesia, and ischemic pain: the effects of contextual variables. J. Abnorm. Psychol. 96(4), 313-320.

Swain, N.R., \& Trevena, J., 2014. A comparison of therapist-present or therapist-free delivery of very brief mindfulness and hypnosis for acute experimental pain. New Zealand Journal of Psychology. 43(3), 22-28.

Tanner-Smith, E.E., \& Tipton, E., 2014. Robust variance estimation with dependent effect sizes: practical considerations including a software tutorial in Stata and SPSS. Res Synth Methods. 5(1), 13-30.

Tenenbaum, S.J., Kurtz, R.M., \& Bienias, J.L., 1990. Hypnotic susceptibility and experimental pain reduction. Am J Clin Hypn. 33(1), 40-49.

Terhune, D.B., \& Cardeña, E., 2016. Nuances and Uncertainties Regarding Hypnotic Inductions: Toward a Theoretically Informed Praxis. Am J Clin Hypn. 59(2), 155-174.

Thompson, T., Oram, C., Correll, C.U., Tsermentseli, S., \& Stubbs, B., 2017a. Analgesic Effects of Alcohol: A Systematic Review and Meta-Analysis of Controlled Experimental Studies in Healthy Participants. J Pain. 18(5), 499-510.

Thompson, T., Steffert, T., Steed, A., \& Gruzelier, J., 2011. A randomized controlled trial of the effects of hypnosis with 3-D virtual reality animation on tiredness, mood, and salivary cortisol. Int J Clin Exp Hypn. 59(1), 122-142.

Thompson, T. et al., 2017b. Pain perception in Parkinson's disease: A systematic review and meta-analysis of experimental studies. Ageing Res Rev. 35, 74-86.

Thompson, T., Mendoza, M.E., \& Docking, R., 2017c. Pain Management and Assessment, in: R. E. Docking \& J. Stock (Eds.), International Handbook of Positive Aging (pp. 115-131). London, UK: Routledge.

Valentini, E., Betti, V., Hu, L., \& Aglioti, S.M., 2013. Hypnotic modulation of pain perception and of brain activity triggered by nociceptive laser stimuli. Cortex. 49(2), 446-462.

Van Gorp, W.G., Meyer, R.G., \& Dunbar, K.D., 1985. The efficacy of direct versus indirect hypnotic induction techniques on reduction of experimental pain. Int J Clin Exp Hypn. 33(4), 319-328.

Vanhaudenhuyse, A. et al., 2009. Pain and non-pain processing during hypnosis: a thulium-YAG event-related fMRI study. Neuroimage. 47(3), 1047-1054.

Viechtbauer, W., \& Cheung, M.W., 2010. Outlier and influence diagnostics for metaanalysis. Res Synth Methods. 1(2), 112-125.

Viechtbauer, W., 2010. Metafor: meta-analysis package for R. R package version. 2010, 1-0.

Weitzenhoffer, A.M., \& Hilgard, E.R., 1962. Stanford hypnotic susceptibility scale, 
form C. Consulting Psychologists Press, Palo Alto, US

Whalley, M.G., \& Brooks, G.B., 2009. Enhancement of suggestibility and imaginative ability with nitrous oxide. Psychopharmacology (Berl). 203(4), 745-752.

Williams, J.D., Croft, R.J., Ferdinand, J., \& Gruzelier, J.H., 2010. Hypnotic analgesia affects the processing of painful stimuli. Australian Journal of Clinical \& Experimental Hypnosis. 38(2), 77-90.

Wolf, T.G. et al., 2016. Effectiveness of Self-Hypnosis on the Relief of Experimental Dental Pain: A Randomized Trial. Int J Clin Exp Hypn. 64(2), 187-199.

Wood, D.R., 1976. The differential effects of hypnosis, rationale, and self-talk in coping with pain on the cold pressor test. PhD. Doctoral dissertation, University of Ottawa, Canada.

Wright, B.R., \& Drummond, P.D., 2001. The effect of rapid induction analgesia on subjective pain ratings and pain tolerance. Int J Clin Exp Hypn. 49(2), 109-122. Yaqub, F., 2015. Pain in the USA: states of suffering. Lancet. 386(9996), 839. Zachariae, R., Andersen, O.K., Bjerring, P., Jørgensen, M.M., \& Arendt-Nielsen, L., 1998. Effects of an opioid antagonist on pain intensity and withdrawal reflexes during induction of hypnotic analgesia in high- and low-hypnotizable volunteers. European Journal of Pain. 2(1), 25-34.

Zachariae, R., \& Bjerring, P., 1994. Laser-induced pain-related brain potentials and sensory pain ratings in high and low hypnotizable subjects during hypnotic suggestions of relaxation, dissociated imagery, focused analgesia, and placebo. Int J Clin Exp Hypn. 42(1), 56-80. 
Table 1. Summary characteristics of included studies.

\begin{tabular}{|c|c|c|c|c|c|c|c|c|c|}
\hline Study & $\begin{array}{l}\text { Study } \\
\text { Design }\end{array}$ & $\begin{array}{l}\text { N } \\
\text { Hyp }\end{array}$ & $\begin{array}{l}\mathrm{N} \\
\text { Control }\end{array}$ & Hypnotic Induction Procedure & Delivery & $\begin{array}{l}\text { Analgesic } \\
\text { Suggestion }\end{array}$ & Control Procedure & $\begin{array}{l}\text { Pain } \\
\text { Induction }\end{array}$ & $\begin{array}{l}\text { Pain } \\
\text { Measure }\end{array}$ \\
\hline Derbyshire et al, 2017 & $\mathrm{RM}$ & 15 & 15 & $\begin{array}{l}\text { Standard hypnotic instructions with relaxation } \\
\text { and imagery including suggestions to alter pain } \\
\text { (e.g. to imagine pain on a dial with instructions } \\
\text { to turn the dial down) }\end{array}$ & Live & Yes, No & Nothing & Heat & Intensity \\
\hline Bhatt et al, 2017 & RM & 14 & 14 & $\begin{array}{l}\text { Standard hypnotic procedure lasting } 30 \text { mins } \\
\text { with relaxation and positive imagery with } \\
\text { analgesic suggestion (e.g. 'imagine the arm } \\
\text { being completely filled with sensation of relief') }\end{array}$ & Live & Yes & Nothing & Heat & $\begin{array}{l}\text { Intensity } \\
\text { Threshold } \\
\text { Tolerance }\end{array}$ \\
\hline Fidanza et al, 2017 & RM & 51 & 51 & $\begin{array}{l}\text { Standard hypnotic instructions with and without } \\
\text { glove analgesia }\end{array}$ & NS & Yes, No & Nothing & Electric & Intensity \\
\hline Casiglia et al, 2017 & RM & 8 & 8 & $\begin{array}{l}\text { Standard hypnotic induction with disassociation } \\
\text { (e.g. 'the hand no longer belongs to the body') }\end{array}$ & Live & No & Nothing & Cold & $\begin{array}{l}\text { Intensity } \\
\text { Tolerance }\end{array}$ \\
\hline Braboszcz et al, 2017 & RM & 11 & 11 & $\begin{array}{l}\text { Standard hypnotic induction with relaxation and } \\
\text { pleasant imagery plus analgesic suggestion (e.g. } \\
\text { 'your arm cannot feel anything') }\end{array}$ & $\begin{array}{l}\text { Live through } \\
\text { headphones }\end{array}$ & Yes & Nothing & Heat & Threshold \\
\hline Wolf et al, 2016 & RM & 37 & 37 & Standard hypnotic induction & Live & No & Nothing & Pressure & $\begin{array}{l}\text { Intensity } \\
\text { Threshold }\end{array}$ \\
\hline De Pascalis et al, 2016 & RM & 51 & 51 & Stanford Hypnotic Clinical Scale & Live & No & $\begin{array}{l}\text { Nothing, but told } \\
\text { may receive } \\
\text { analgesic or sham } \\
\text { cream }\end{array}$ & Cold & Affect \\
\hline De Pascalis et al, 2015 & RM & 20 & 20 & Stanford Hypnotic Clinical Scale & Live & Yes, No & Relaxation & Electric & $\begin{array}{l}\text { Intensity } \\
\text { Affect }\end{array}$ \\
\hline Kramer et al, 2014 & RM & 23 & 23 & Fixation method + recall feelings of wellbeing & Live & No & Nothing & $\begin{array}{l}\text { Cold }+ \text { Heat } \\
+ \text { Pressure }\end{array}$ & Threshold \\
\hline Swain et al, 2014 & RM & 120 & 120 & *Standard hypnotic induction & Live / DVD & No & Nothing & Cold & $\begin{array}{l}\text { Intensity } \\
\text { Tolerance }\end{array}$ \\
\hline Enea et al, 2014 & PPC & 60 & 30 & Stanford SHSS:C & Live & Yes & Nothing & Pressure & $\begin{array}{l}\text { Intensity } \\
\text { Affect }\end{array}$ \\
\hline Valentini et al, 2013 & RM & 24 & 24 & Stanford SHSS:A & Live & Yes & Nothing & Heat & $\begin{array}{l}\text { Intensity } \\
\text { Affect }\end{array}$ \\
\hline
\end{tabular}




\section{HYPNOSIS AND PAIN}

\begin{tabular}{|c|c|c|c|c|c|c|c|c|c|}
\hline $\begin{array}{l}\text { Santarcangelo et al, } \\
2013\end{array}$ & RM & 40 & 40 & $\begin{array}{l}\text { Standard hypnotic induction with relaxation and } \\
\text { pleasant imagery, plus glove analgesic } \\
\text { suggestion (e.g. 'you cannot feel pain because } \\
\text { the glove you are wearing prevents you from } \\
\text { feeling it') }\end{array}$ & Live & Yes & Nothing & Cold & $\begin{array}{l}\text { Intensity } \\
\text { Threshold }\end{array}$ \\
\hline Goodin et al, 2012 & PPC & 12 & 12 & $\begin{array}{l}\text { Modified verbal, movement and eye fixation } \\
\text { method + glove analgesia }\end{array}$ & Live & Yes & Nothing & Cold & $\begin{array}{l}\text { Intensity } \\
\text { Affect } \\
\text { Tolerance }\end{array}$ \\
\hline Facco et al, 2011 & RM & 31 & 31 & $\begin{array}{l}\text { Hypnosis with relaxation and well-being } \\
\text { suggestions }\end{array}$ & Live & Yes & Nothing & Electric & Threshold \\
\hline Milling et al, 2010b & RM & 173 & 173 & Hypnosis as per Spanos (1977) & Live & Yes & Nothing & Pressure & Intensity \\
\hline $\begin{array}{l}\text { Milling et al, 2010a } \\
\text { ( } 2 \text { experiments) }\end{array}$ & PPC & $\begin{array}{l}52 \\
143\end{array}$ & $\begin{array}{l}52 \\
143\end{array}$ & $\begin{array}{l}\text { Standard hypnotic induction + glove analgesic } \\
\text { suggestion + relaxation }\end{array}$ & Live & Yes & Nothing & Pressure & Intensity \\
\hline Green et al, 2010 & BG & 26 & 24 & $\begin{array}{l}\text { Stanford Hypnotic Clinical Scale + glove } \\
\text { analgesic suggestion }\end{array}$ & Live & Yes & Nothing & Ischemic & Intensity \\
\hline Williams et al, 2010 & RM & 33 & 33 & Standard hypnotic induction & Live & Yes, No & Not reported & Electric & Intensity \\
\hline Milling et al, 2009 & PPC & 46 & 83 & $\begin{array}{l}\text { CURSS hypnotic induction with \& without } 45 \text {-sec } \\
\text { glove analgesic suggestion }\end{array}$ & Live & Yes, No & $\begin{array}{l}\text { Placebo- sham oil } \\
\text { labelled Trivaricaine } \\
\text { Nothing }\end{array}$ & Pressure & Intensity \\
\hline $\begin{array}{l}\text { Vanhaudenhuyse et } \\
\text { al, } 2009\end{array}$ & RM & 13 & 13 & Relaxation, fixation + memory recall & Live & No & Nothing & Laser & Intensity \\
\hline De Pascalis, 2008 & RM & 36 & 36 & Stanford SHSS:C & Live & Yes, No & Nothing & Electric & $\begin{array}{l}\text { Intensity } \\
\text { Affect }\end{array}$ \\
\hline Roder et al, 2007 & RM & 7 & 7 & $\begin{array}{l}\text { Hypnosis + Fixation + relaxation } \\
\text { Hypnosis +Fixation + depersonalization }\end{array}$ & Live & No & Nothing & Electric & Intensity \\
\hline Casgalia et al, 2007 & RM & 20 & 20 & $\begin{array}{l}\text { Hypnosis with suggestion of relaxation and } \\
\text { analgesia }\end{array}$ & Live & Yes & Nothing & Cold & $\begin{array}{l}\text { Intensity } \\
\text { Tolerance }\end{array}$ \\
\hline Milling et al, 2007 & PPC & 42 & 41 & CURSS & Live & Yes & $\begin{array}{l}\text { Placebo- sham oil } \\
\text { labelled Trivaricaine } \\
\text { Nothing }\end{array}$ & Pressure & Intensity \\
\hline Sharav et al, 2006 & RM & 25 & 25 & $\begin{array}{l}\text { Hypnotic induction with generalized relaxation, } \\
\text { guided imagery and focused analgesia }\end{array}$ & Live & Yes & Nothing & Electric & Intensity \\
\hline Patterson et al, 2006 & PPC & 51 & 26 & $\begin{array}{l}\text { Stanford Hypnotic Clinical Scale with relaxation } \\
+ \text { analgesic/no analgesic suggestion }\end{array}$ & $\begin{array}{l}\text { Audio } \\
\text { recording }\end{array}$ & Yes, No & Nothing & Heat & $\begin{array}{l}\text { Intensity } \\
\text { Affect }\end{array}$ \\
\hline Milling et al, 2005 & RM & 40 & 40 & CURSS + glove analgesic suggestion & Live & Yes & $\begin{array}{l}\text { Placebo topical oil } \\
\text { Nothing }\end{array}$ & Pressure & Intensity \\
\hline
\end{tabular}




\section{HYPNOSIS AND PAIN}

\begin{tabular}{|c|c|c|c|c|c|c|c|c|c|}
\hline Rainville et al, 2005 & RM & 69 & 69 & Standard hypnotic induction & Live & No & Nothing & Heat & $\begin{array}{l}\text { Intensity } \\
\text { Affect }\end{array}$ \\
\hline $\begin{array}{l}\text { De Pascalis, Cacace et } \\
\text { al, } 2004\end{array}$ & RM & 38 & 38 & Stanford SHSS:C & Live & Yes, No & Nothing & Electric & $\begin{array}{l}\text { Intensity } \\
\text { Affect }\end{array}$ \\
\hline $\begin{array}{l}\text { De Pascalis, Bellusci } \\
\text { et al, } 2004\end{array}$ & RM & 30 & 30 & Stanford SHSS:C with relaxation + dissociation & Live & Yes, No & Placebo & Cold & Intensity \\
\hline Sharav et al, 2004 & RM & 15 & 15 & $\begin{array}{l}\text { Hypnotic relaxation induction with/without } \\
\text { focused analgesic suggestion }\end{array}$ & Live & Yes, No & Nothing & Electric & Intensity \\
\hline $\begin{array}{l}\text { Milling and Breen, } \\
2003\end{array}$ & PPC & 55 & 55 & $\begin{array}{l}\text { CURSS with pain control or glove analgesic } \\
\text { suggestion }\end{array}$ & $\begin{array}{l}\text { Audio } \\
\text { recording }\end{array}$ & Yes, No & $\begin{array}{l}\text { Placebo- sham oil } \\
\text { labelled Trivaricaine } \\
\text { Nothing }\end{array}$ & Pressure & Intensity \\
\hline $\begin{array}{l}\text { Milling, Levine et al, } \\
2003\end{array}$ & PPC & 95 & 47 & CURSS & Live & Yes, No & Nothing & Pressure & Intensity \\
\hline $\begin{array}{l}\text { Faymonville et al, } \\
2003\end{array}$ & RM & 19 & 19 & $\begin{array}{l}\text { Hypnosis with eye fixation and muscle } \\
\text { relaxation }\end{array}$ & Live & Yes & Nothing & Heat & Intensity \\
\hline Croft et al, 2002 & BG & 11 & 9 & Hypnosis with relaxation, fixation and imagery & Live & Yes, No & Oddball task & Electric & Intensity \\
\hline Milling et al, 2002 & PPC & 22 & 18 & CURSS + glove analgesia & Live & Yes & Nothing & Pressure & Intensity \\
\hline Langlade et al, 2002 & RM & 15 & 15 & $\begin{array}{l}\text { Hypnosis with fixation, relaxation and analgesic } \\
\text { suggestion }\end{array}$ & Live & Yes & Nothing & Heat & $\begin{array}{l}\text { Threshold } \\
\text { Tolerance }\end{array}$ \\
\hline Ray et al, 2002 & RM & 12 & 12 & Stanford SHSS:C & $\begin{array}{l}\text { Audio } \\
\text { recording }\end{array}$ & Yes & Nothing & Electric & Intensity \\
\hline Friederich et al, 2001 & RM & 20 & 20 & $\begin{array}{l}\text { Stanford Hypnotic Clinical Scale } \\
\text { glove analgesic suggestion + relaxation imagery }\end{array}$ & Live & Yes & Nothing & Heat & $\begin{array}{l}\text { Intensity } \\
\text { Affect }\end{array}$ \\
\hline Wright et al, 2001 & PPC & 30 & 28 & Rapid induction Analgesia & Live & Yes & Reading & $\begin{array}{l}\text { Chemical } \\
\text { Pressure }\end{array}$ & $\begin{array}{l}\text { Intensity } \\
\text { Affect } \\
\text { Threshold } \\
\text { Tolerance }\end{array}$ \\
\hline De Pascalis et al, 2001 & RM & 29 & 29 & $\begin{array}{l}\text { Stanford SHSS: } \mathrm{C} \text { with relaxation, dissociation } \\
\text { and analgesic suggestion }\end{array}$ & Live & Yes, No & $\begin{array}{l}\text { Nothing } \\
\text { Placebo topical } \\
\text { anaesthetic }\end{array}$ & Electric & $\begin{array}{l}\text { Intensity } \\
\text { Affect }\end{array}$ \\
\hline Benhaiem et al, 2001 & RM & 32 & 32 & $\begin{array}{l}\text { Hypnosis with deep relaxation and focused } \\
\text { analgesia }\end{array}$ & Live & Yes, No & Nothing & Heat & Threshold \\
\hline
\end{tabular}




\section{HYPNOSIS AND PAIN}

\begin{tabular}{|c|c|c|c|c|c|c|c|c|c|}
\hline Hofbauer et al, 2001 & RM & 10 & 10 & Stanford SHSS:A & Live & Yes, No & Nothing & Heat & $\begin{array}{l}\text { Intensity } \\
\text { Affect }\end{array}$ \\
\hline $\begin{array}{l}\text { Faymonville et al, } \\
2000\end{array}$ & RM & 11 & 11 & $\begin{array}{l}\text { Stanford SHSS:C with muscle relaxation and } \\
\text { pleasant memory recall }\end{array}$ & Live & No & Nothing & Heat & $\begin{array}{l}\text { Intensity } \\
\text { Affect }\end{array}$ \\
\hline Sandrini et al, 2000 & RM & 20 & 20 & Standard hypnotic induction & Live & Yes & Nothing & Cold & Tolerance \\
\hline De Pascalis et al, 1999 & RM & 29 & 29 & $\begin{array}{l}\text { Stanford SHSS:C with relaxation, dissociative } \\
\text { imagery and analgesic suggestion }\end{array}$ & Live & Yes, No & $\begin{array}{l}\text { Nothing } \\
\text { Placebo topical gel }\end{array}$ & Electric & $\begin{array}{l}\text { Intensity } \\
\text { Affect } \\
\text { Threshold }\end{array}$ \\
\hline Rainville et al, 1999 & PPC & 11 & 6 & Stanford SHSS:A & Live & Yes & Nothing & Heat & $\begin{array}{l}\text { Intensity } \\
\text { Affect }\end{array}$ \\
\hline Milling et al, 1999 & PPC & 50 & 48 & Stanford SHSS:C & $\begin{array}{l}\text { Audio } \\
\text { recording }\end{array}$ & Yes & Nothing & Pressure & Intensity \\
\hline Danziger et al, 1998 & RM & 18 & 18 & $\begin{array}{l}\text { Hypnosis with deep relaxation, fixation and } \\
\text { Analgesic suggestion }\end{array}$ & Live & Yes & Nothing & Electric & Threshold \\
\hline Zachariae et al, 1998 & RM & 20 & 20 & Standard hypnotic induction & Live & Yes, No & Nothing & Electric & Intensity \\
\hline Rainville et al, 1997 & RM & 8 & 8 & Stanford SHSS:A & Live & Yes, No & Nothing & Heat & $\begin{array}{l}\text { Intensity } \\
\text { Affect }\end{array}$ \\
\hline De Pascalis et al, 1997 & RM & 20 & 20 & $\begin{array}{l}\text { Stanford SHSS:C with subjective sensitivity to } \\
\text { somatosensory stimuli emphasised }\end{array}$ & $\begin{array}{l}\text { Audio } \\
\text { recording }\end{array}$ & Yes, No & $\begin{array}{l}\text { 'normal attention' } \\
\text { control } \\
\text { (recognition task) }\end{array}$ & Electric & $\begin{array}{l}\text { Intensity } \\
\text { Threshold }\end{array}$ \\
\hline De Pascalis et al, 1996 & RM & 16 & 16 & Stanford SHSS:C & Live & Yes, No & Nothing & Electric & $\begin{array}{l}\text { Intensity } \\
\text { Affect }\end{array}$ \\
\hline Jacobs et al, 1995 & RM & 24 & 24 & Stanford SHSS:C & $\begin{array}{l}\text { Audio } \\
\text { recording }\end{array}$ & Yes & Nothing & Cold & Intensity \\
\hline Kiernan et al, 1995 & RM & 15 & 15 & $\begin{array}{l}\text { Hypnosis with suggestion of relaxation, comfort, } \\
\text { and wellbeing }\end{array}$ & Live & Yes & Nothing & Electric & $\begin{array}{l}\text { Intensity } \\
\text { Affect }\end{array}$ \\
\hline Hargadon et al, 1995 & RM & 66 & 66 & $\begin{array}{l}\text { Standard hypnotic induction with glove } \\
\text { analgesic suggestion }\end{array}$ & Live & Yes & Nothing & Pressure & Intensity \\
\hline Dahlgren et al, 1995 & RM & 16 & 16 & $\begin{array}{l}\text { Stanford hypnotic clinical scale with deep } \\
\text { relaxation }\end{array}$ & Live & Yes & Nothing & Cold & $\begin{array}{l}\text { Intensity } \\
\text { Affect }\end{array}$ \\
\hline Zachariae et al, 1994 & RM & 20 & 20 & $\begin{array}{l}\text { Hypnosis using eye fixation technique and } \\
\text { standardised countdown deepening procedure } \\
\text { with deep relaxation/ dissociative imagery/ } \\
\text { focused analgesia }\end{array}$ & Live & Yes, No & $\begin{array}{l}\text { Placebo } \\
\text { anaesthetic spray }\end{array}$ & Laser & Intensity \\
\hline
\end{tabular}




\section{HYPNOSIS AND PAIN}

\begin{tabular}{|c|c|c|c|c|c|c|c|c|c|}
\hline Crawford et al, 1993 & RM & 11 & 11 & $\begin{array}{l}\text { Stanford SHSS:C with mention of sleep and } \\
\text { drowsiness }\end{array}$ & NG & Yes, No & Nothing & Ischemic & $\begin{array}{l}\text { Intensity } \\
\text { Affect }\end{array}$ \\
\hline Maurer et al, 1993 & RM & 42 & 42 & $\begin{array}{l}\text { Direct hypnosis induction with focused attention } \\
\text { and repetitive direct suggestion } \\
\text { Indirect hypnosis with 'Rapid Induction } \\
\text { Analgesia' }\end{array}$ & Live & Yes & Nothing & Cold & Intensity \\
\hline $\begin{array}{l}\text { Spanos et al, } 1990 \\
\text { ( } 2 \text { experiments) }\end{array}$ & $\begin{array}{l}\text { PPC } \\
\text { (RM) }\end{array}$ & $\begin{array}{l}15 \\
28\end{array}$ & $\begin{array}{l}15 \\
28\end{array}$ & Hypnosis (Barber, 1969) & $\begin{array}{l}\text { Audio } \\
\text { recording }\end{array}$ & Yes & Nothing & Pressure & Intensity \\
\hline $\begin{array}{l}\text { Tenenbaum et al, } \\
1990\end{array}$ & RM & 48 & 48 & Stanford Hypnotic Clinical Scale & $\begin{array}{l}\text { Audio } \\
\text { recording }\end{array}$ & Yes & Nothing & Cold & Tolerance \\
\hline Malone et al, 1989 & RM & 45 & 45 & $\begin{array}{l}\text { Hypnosis (Barber, 1969) with relaxation and } \\
\text { analgesic suggestion }\end{array}$ & Live & Yes, No & Nothing & Electric & $\begin{array}{l}\text { Intensity } \\
\text { Affect }\end{array}$ \\
\hline $\begin{array}{l}\text { Spanos, Perlini et al, } \\
1989 \\
2 \text { experiments }\end{array}$ & PPC & $\begin{array}{l}64 \\
60\end{array}$ & $\begin{array}{l}32 \\
30\end{array}$ & Hypnosis (Barber, 1969) & Live & Yes & Nothing & Pressure & Intensity \\
\hline $\begin{array}{l}\text { Spanos and Katsanis, } \\
1989\end{array}$ & PPC & 20 & 10 & $\begin{array}{l}\text { Hypnosis modified from Barber (1969) as } \\
\text { passively (analgesia without voluntary effort) or } \\
\text { actively (analgesia due to mental control) } \\
\text { worded instructions }\end{array}$ & Live & Yes & Nothing & Pressure & Intensity \\
\hline $\begin{array}{l}\text { De Benedettis et al, } \\
1989\end{array}$ & RM & 21 & 21 & Standard hypnotic induction & Live & Yes` & Nothing & Ischemic & $\begin{array}{l}\text { Affect } \\
\text { Tolerance }\end{array}$ \\
\hline Spanos et al, 1988 & PPC & 45 & 15 & Hypnosis (Barber, 1969) & Live & Yes & Nothing & Pressure & Tolerance \\
\hline Price et al, 1987 & RM & 16 & 16 & Standard hypnotic induction & Live & Yes & Nothing & Heat & $\begin{array}{l}\text { Intensity } \\
\text { Affect }\end{array}$ \\
\hline Stam et al, 1987 & RM & 32 & 32 & Standard hypnotic Induction & Live & Yes & Nothing & Ischemic & $\begin{array}{l}\text { Thresholc } \\
\text { Tolerance }\end{array}$ \\
\hline Spanos et al, 1986 & PPC & 64 & 32 & Hypnosis (Barber, 1969) & $\begin{array}{l}\text { Audio } \\
\text { recording }\end{array}$ & Yes & Nothing & Pressure & $\begin{array}{l}\text { Intensity } \\
\text { Tolerance }\end{array}$ \\
\hline Van Gorp et al, 1985 & PPC & 20 & 20 & $\begin{array}{l}\text { Rapid induction analgesia which includes } \\
\text { suggestion of relaxation and altering memory } \\
\text { Standard hypnotic induction }\end{array}$ & $\begin{array}{l}\text { Audio } \\
\text { recording }\end{array}$ & Yes, No & Nothing & Cold & Intensity \\
\hline Spanos et al, 1985 & PPC & 21 & 19 & Hypnosis (Barber, 1969) & $\begin{array}{l}\text { Audio } \\
\text { recording }\end{array}$ & Yes & Nothing & Cold & Tolerance \\
\hline
\end{tabular}




\section{HYPNOSIS AND PAIN}

\begin{tabular}{|c|c|c|c|c|c|c|c|c|c|}
\hline Fricton et al, 1985 & RM & 10 & 10 & $\begin{array}{l}\text { Indirect hypnosis induction uses language that is } \\
\text { individualised - implies control rests with the } \\
\text { subject } \\
\text { Direct hypnosis induction uses focused attention } \\
\text { and repetitive direct suggestion }\end{array}$ & Live & No & Nothing & Electric & Threshold \\
\hline Spanos et al, 1984 & RM & 75 & 75 & Hypnosis (Barber, 1969) & Live & Yes & Nothing & Cold & Intensity \\
\hline $\begin{array}{l}\text { Stam et al, } 1984 \\
\text { ( } 2 \text { experiments) }\end{array}$ & $\begin{array}{l}\mathrm{RM} \\
\text { (PPC) }\end{array}$ & $\begin{array}{l}16 \\
10\end{array}$ & $\begin{array}{l}16 \\
10\end{array}$ & Standard hypnotic induction & $\begin{array}{l}\text { Audio } \\
\text { recording }\end{array}$ & Yes & Nothing & Ischemic & $\begin{array}{l}\text { Threshold } \\
\text { Tolerance }\end{array}$ \\
\hline Spanos et al, 1983 & RM & 16 & 16 & $\begin{array}{l}\text { Hypnosis (Barber, 1969) with suggestions of } \\
\text { more or less aware of pain from overt and } \\
\text { hidden part of body }\end{array}$ & $\begin{array}{l}\text { Audio } \\
\text { recording }\end{array}$ & Yes & Nothing & Cold & Intensity \\
\hline Karlin et al, 1980 & RM & 11 & 11 & Standard hypnotic induction & $\begin{array}{l}\text { Audio } \\
\text { recording }\end{array}$ & Yes & Nothing & Cold & Intensity \\
\hline Spanos et al, 1980 & RM & 8 & 8 & Hypnotic induction with hidden observer cues & $\begin{array}{l}\text { Audio } \\
\text { recording }\end{array}$ & Yes & Nothing & Cold & Intensity \\
\hline Stam et al, 1980 & PPC & 20 & 10 & Standard hypnotic procedure & Live & Yes & Nothing & Cold & Intensity \\
\hline Wood et al, 1976 & PPC & 10 & 10 & Standard hypnotic induction & $\begin{array}{l}\text { Audio } \\
\text { recording }\end{array}$ & No & Nothing & Cold & Tolerance \\
\hline Lli et al, 1975 & RM & 14 & 14 & Standard hypnotic induction with relaxation & Live & Yes & Nothing & Electric & $\begin{array}{l}\text { Tolerance } \\
\text { Threshold }\end{array}$ \\
\hline Greene et al, 1972 & RM & 36 & 36 & $\begin{array}{l}\text { Standard hypnotic induction with pleasant } \\
\text { imager with/without analgesic suggestion }\end{array}$ & Live & Yes, No & Nothing & Electric & Tolerance \\
\hline Morgan et al, 1970 & RM & 12 & 12 & Standard hypnotic induction & NG & Yes & Nothing & Cold & Intensity \\
\hline Evans et al, 1970 & PPC & 32 & 16 & $\begin{array}{l}\text { Hypnotic induction with eye fixation \& } \\
\text { relaxation }\end{array}$ & Live & Yes, No & Nothing & Cold & Affect \\
\hline
\end{tabular}

Key. RM=repeated-measures; BG=between-groups; PPC=pre-post control; CURSS=Carlton University Responsiveness to Suggestion Scale; SHSS=Stanford Hypnotic Suggestibility Scale (Forms A and C). 
HYPNOSIS AND PAIN

Table 2. Meta-regression estimates of unstandardized (0-10) pain intensity ratings and $95 \%$ confidence intervals $(\mathrm{Cl})$.

\begin{tabular}{llll}
\hline & Estimate & $95 \% \mathrm{Cl}$ & $\mathrm{p}$ \\
\hline Intercept & 0.03 & $-0.59,0.64$ & .931 \\
Hypnotisability (Medium) & 0.64 & $0.26,1.03$ & .003 \\
Hypnotisability (High) & 1.34 & $0.75,1.93$ & $<.001$ \\
Analgesic suggestion (Yes) & 0.94 & $0.25,1.63$ & .009 \\
\hline
\end{tabular}


Figure 1. PRISMA flow diagram
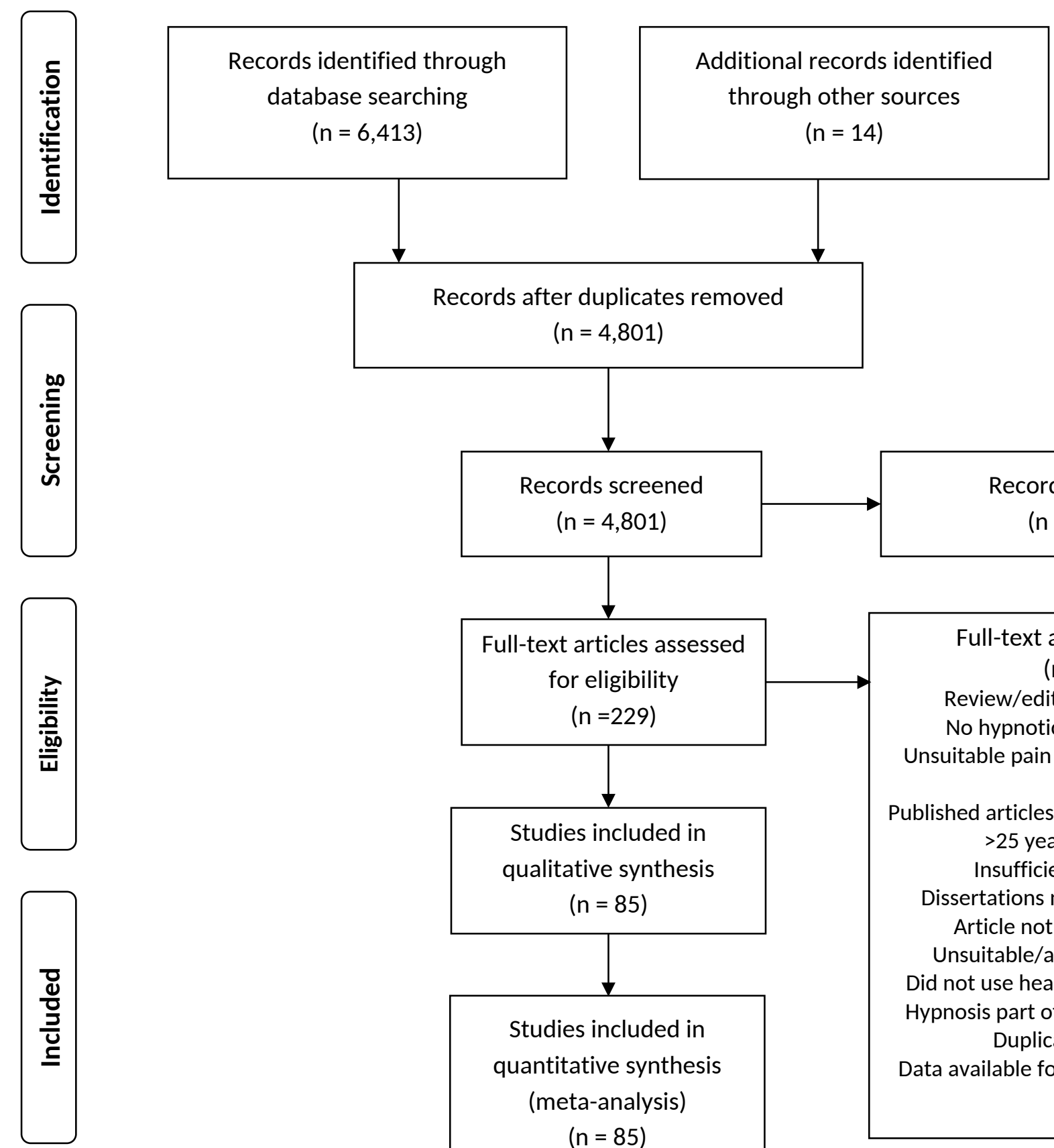

$(n=4,801)$
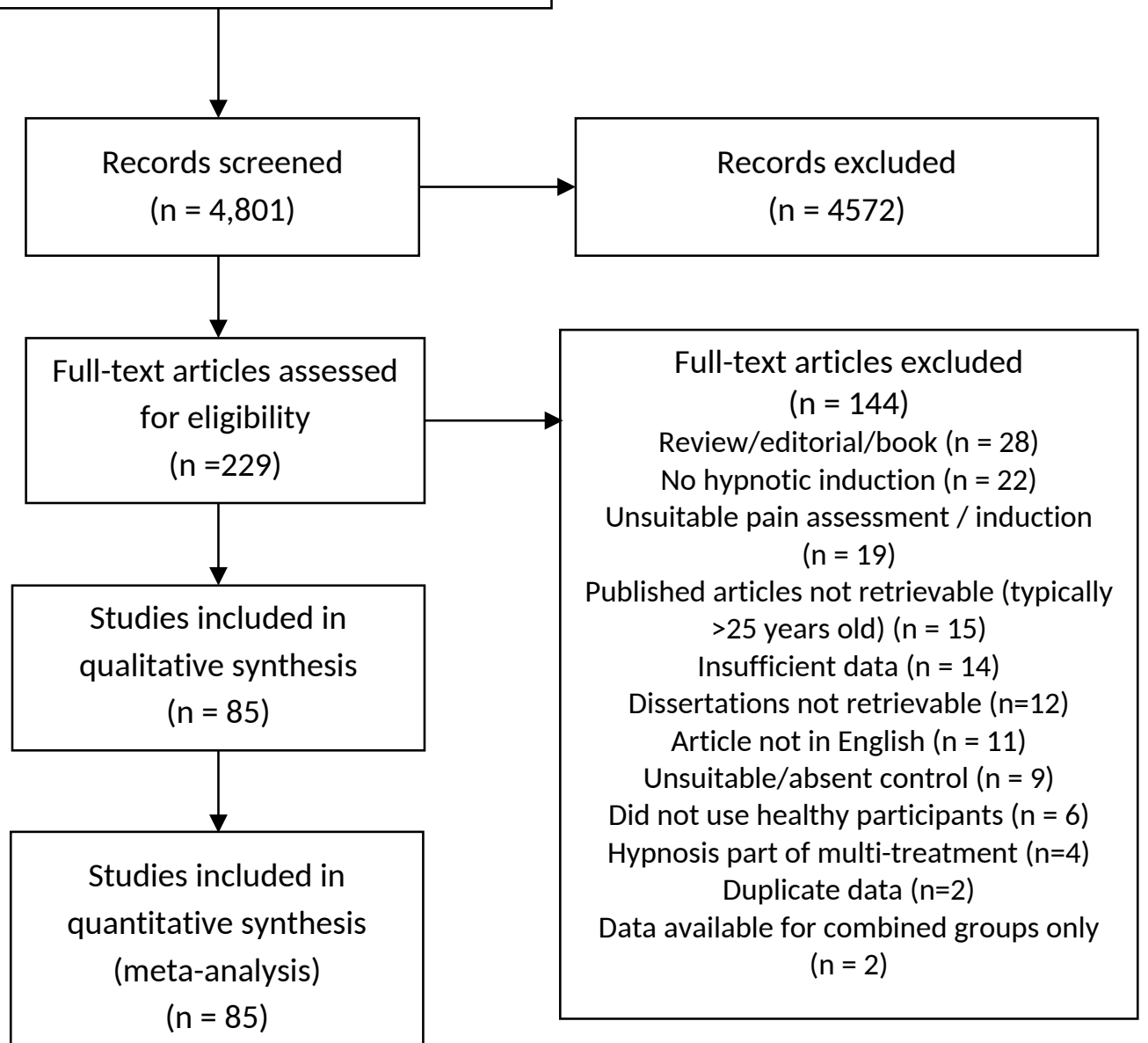
Figure 2. Forest plot of pain intensity

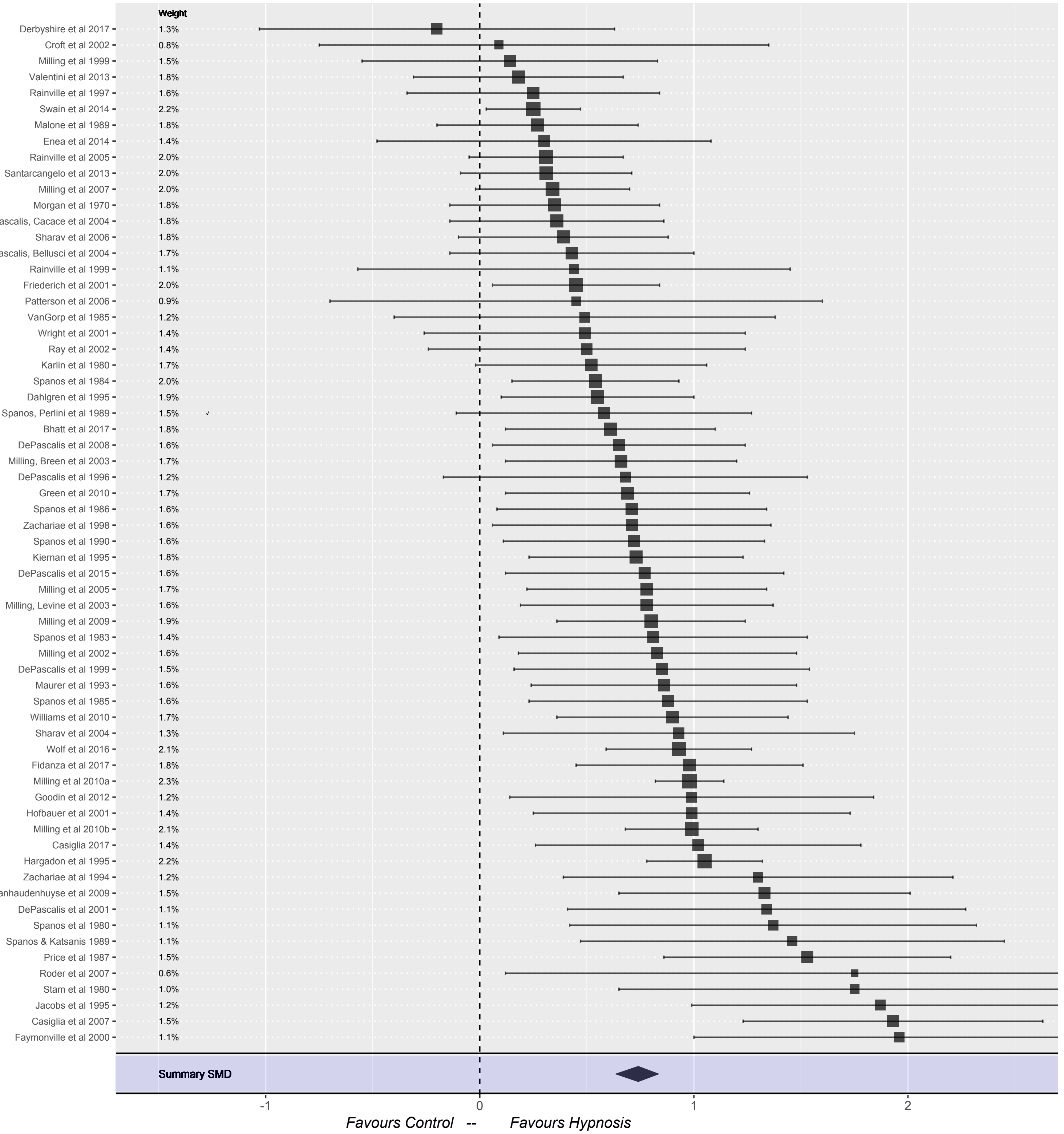


Appendix S1. Search terms for PubMed

(hypno* OR trance) AND (pain OR nocicept* OR analge*) AND (threshold OR tolerance OR cold OR heat OR thermal OR ischemi* OR ischaemi* OR chemical OR pressure OR mechanical OR electric* OR chemical OR capsaicin OR reflex OR experimental OR acute) 
Appendix S2. Endorsement of validity criteria (1= criteria met, $0=$ criteria not met)

\begin{tabular}{|c|c|c|c|c|c|c|c|c|c|c|c|c|c|c|c|}
\hline Study & q1 & q2 & q3 & q4 & q5 & q6 & q7 & q8 & q9 & q10 & q11 & q12 & q13 & q14 & q15 \\
\hline Derbyshire et al (2017) & 1 & 1 & 1 & 0 & 0 & 0 & 1 & 1 & 1 & 0 & 1 & 1 & 1 & 1 & 1 \\
\hline Bhatt et al (2017) & 1 & 1 & 0 & 1 & 1 & 0 & 1 & 1 & 1 & 1 & 0 & 1 & 1 & 1 & 0 \\
\hline Fidanza et al (2017) & 1 & 1 & 0 & 1 & 0 & 1 & 1 & 1 & 0 & 0 & 1 & 1 & 1 & 1 & 0 \\
\hline Casiglia et al (2017) & 1 & 0 & 0 & 0 & 0 & 0 & 1 & 1 & 0 & 0 & 0 & 1 & 0 & 1 & 0 \\
\hline Braboszcz et al (2017) & 1 & 1 & 1 & 0 & 0 & 0 & 0 & 1 & 1 & 1 & 1 & 1 & 1 & 1 & 1 \\
\hline Wolf et al (2016) & 1 & 1 & 1 & 1 & 0 & 1 & 0 & 1 & 1 & 0 & 0 & 1 & 0 & 1 & 1 \\
\hline DePascalis et al (2016) & 1 & 1 & 1 & 1 & 1 & 1 & 1 & 1 & 0 & 1 & 1 & 1 & 1 & 1 & 0 \\
\hline DePascalis et al (2015) & 1 & 1 & 1 & 1 & 0 & 1 & 1 & 1 & 1 & 1 & 1 & 0 & 1 & 1 & 1 \\
\hline Kramer et al (2014) & 1 & 0 & 1 & 1 & 0 & 0 & 1 & 1 & 1 & 0 & 1 & 1 & 1 & 1 & 0 \\
\hline Swain et al (2014) & 1 & 1 & 1 & 1 & 1 & 0 & 1 & 1 & 0 & 1 & 0 & 0 & 1 & 1 & 0 \\
\hline Enea et al (2014) & 1 & 1 & 1 & 0 & 0 & 0 & 1 & 1 & 1 & 1 & 1 & 1 & 0 & 1 & 1 \\
\hline Valentini et al (2013) & 1 & 0 & 0 & 1 & 1 & 1 & 1 & 1 & 1 & 0 & 1 & 1 & 1 & 1 & 1 \\
\hline Santarcangelo et al (2013) & 1 & 1 & 1 & 1 & 1 & 0 & 1 & 1 & 0 & 1 & 1 & 1 & 1 & 1 & 0 \\
\hline Goodin et al (2012) & 1 & 1 & 1 & 1 & 1 & 1 & 1 & 1 & 1 & 1 & 1 & 0 & 1 & 1 & 1 \\
\hline Facco et al (2011) & 1 & 1 & 0 & 1 & 1 & 1 & 1 & 1 & 1 & 0 & 1 & 1 & 1 & 1 & 0 \\
\hline Williams et al (2012) & 1 & 0 & 0 & 0 & 0 & 0 & 1 & 1 & 0 & 0 & 1 & 1 & 1 & 1 & 1 \\
\hline Milling et al (2010) & 1 & 1 & 1 & 0 & 0 & 0 & 1 & 0 & 0 & 1 & 1 & 1 & 1 & 1 & 0 \\
\hline Green et al (2010) & 1 & 1 & 1 & 1 & 1 & 1 & 1 & 1 & 1 & 1 & 1 & 1 & 1 & 1 & 0 \\
\hline Milling et al (2010) & 1 & 1 & 1 & 1 & 1 & 0 & 1 & 1 & 0 & 1 & 0 & 0 & 1 & 1 & 0 \\
\hline Milling et al (2009) & 1 & 1 & 1 & 0 & 1 & 0 & 1 & 1 & 1 & 1 & 1 & 0 & 1 & 1 & 1 \\
\hline Vanhaudenhuyse et al (2009) & 1 & 0 & 1 & 1 & 1 & 1 & 1 & 1 & 1 & 1 & 1 & 1 & 1 & 1 & 1 \\
\hline DePascalis et al (2008) & 1 & 1 & 0 & 1 & 1 & 1 & 1 & 1 & 0 & 1 & 1 & 1 & 1 & 1 & 1 \\
\hline Roder et al (2007) & 1 & 0 & 0 & 0 & 0 & 0 & 1 & 1 & 1 & 0 & 1 & 0 & 1 & 1 & 0 \\
\hline Casiglia et al (2007) & 1 & 0 & 0 & 0 & 0 & 1 & 1 & 1 & 1 & 0 & 0 & 1 & 1 & 1 & 0 \\
\hline Milling et al (2007) & 1 & 1 & 1 & 0 & 0 & 0 & 1 & 1 & 1 & 1 & 1 & 0 & 1 & 1 & 1 \\
\hline Sharav et al (2006) & 1 & 1 & 1 & 0 & 0 & 0 & 1 & 1 & 1 & 0 & 1 & 1 & 1 & 1 & 0 \\
\hline Patterson et al (2006) & 1 & 1 & 0 & 0 & 0 & 0 & 1 & 1 & 1 & 0 & 1 & 0 & 1 & 1 & 1 \\
\hline
\end{tabular}


Milling et al (2005)

Rainville et al (2005)

DePascalis, Cacace et al (2004)

DePascalis, Bellusci et al (2004)

Sharav et al (2004)

Milling, Breen et al (2003)

Faymonville et al (2003)

Milling, Levine et al (2003)

Croft et al (2002)

Milling et al (2002)

Langlade et al (2002)

Ray et al (2002)

Wright et al (2001)

DePascalis et al (2001)

Benhiem et al (2001)

Hofbauer et al (2001)

Freiderich et al (2001)

Faymonville et al (2000)

Sandrini et al (2000)

DePascalis et al (1999)

Rainville et al (1999)

Milling et al (1999)

Danzinger et al (1998)

Zachariae et al (1998)

Rainville et al (1997)

DePascalis et al (1997)

DePascalis et al (1996)

Jacobs et al (1995)

Kiernan et al (1995) 


\begin{tabular}{|c|c|c|c|c|c|c|c|c|c|c|c|c|c|c|c|}
\hline Hargadon et al (1995) & 1 & 0 & 0 & 0 & 0 & 0 & 1 & 1 & 1 & 1 & 1 & 1 & 0 & 1 & 0 \\
\hline Dahlgren et al (1995) & 1 & 1 & 0 & 1 & 0 & 1 & 0 & 0 & 0 & 1 & 1 & 1 & 0 & 1 & 0 \\
\hline Zachariae et al (1994) & 1 & 1 & 1 & 0 & 0 & 0 & 1 & 1 & 1 & 1 & 1 & 1 & 1 & 1 & 1 \\
\hline Maurer et al (1993) & 1 & 1 & 0 & 0 & 0 & 0 & 1 & 1 & 1 & 1 & 1 & 1 & 1 & 1 & 0 \\
\hline Crawford et al (1993) & 1 & 1 & 1 & 1 & 1 & 1 & 1 & 1 & 0 & 1 & 1 & 1 & 1 & 1 & 1 \\
\hline Spanos et al (1990) & 1 & 1 & 1 & 0 & 0 & 0 & 1 & 1 & 1 & 1 & 1 & 0 & 0 & 1 & 1 \\
\hline Tenenbaum et al (1990) & 1 & 0 & 1 & 1 & 0 & 1 & 1 & 1 & 0 & 0 & 1 & 0 & 0 & 1 & 0 \\
\hline Malone et al (1989) & 0 & 1 & 1 & 0 & 0 & 0 & 1 & 1 & 1 & 0 & 1 & 0 & 0 & 1 & 1 \\
\hline Spanos, Perlini et al (1989) & 1 & 1 & 1 & 0 & 0 & 0 & 1 & 1 & 1 & 1 & 1 & 1 & 1 & 1 & 1 \\
\hline Spanos and Katsanis et al (1989) & 1 & 1 & 1 & 0 & 0 & 0 & 1 & 1 & 1 & 1 & 1 & 0 & 0 & 1 & 1 \\
\hline Debenedittis et al (1989) & 1 & 1 & 1 & 0 & 0 & 0 & 1 & 1 & 1 & 0 & 1 & 1 & 1 & 1 & 0 \\
\hline Spanos et al (1988) & 1 & 1 & 1 & 0 & 0 & 0 & 1 & 1 & 1 & 1 & 1 & 0 & 1 & 1 & 1 \\
\hline Stam et al (1987) & 1 & 1 & 1 & 1 & 0 & 1 & 1 & 1 & 0 & 1 & 0 & 1 & 1 & 1 & 0 \\
\hline Price et al (1987) & 1 & 1 & 1 & 0 & 0 & 0 & 1 & 1 & 1 & 0 & 0 & 1 & 1 & 1 & 0 \\
\hline Spanos et al (1986) & 1 & 1 & 1 & 0 & 0 & 0 & 1 & 1 & 1 & 1 & 1 & 1 & 0 & 1 & 1 \\
\hline VanGorp et al (1985) & 1 & 1 & 0 & 0 & 0 & 0 & 1 & 1 & 1 & 1 & 1 & 1 & 0 & 1 & 1 \\
\hline Spanos et al (1985) & 1 & 1 & 1 & 0 & 0 & 0 & 1 & 1 & 1 & 1 & 0 & 1 & 0 & 1 & 1 \\
\hline Fricton et al (1985) & 1 & 0 & 0 & 0 & 0 & 0 & 1 & 1 & 1 & 0 & 1 & 1 & 0 & 1 & 0 \\
\hline Spanos et al (1984) & 1 & 1 & 1 & 0 & 0 & 0 & 1 & 1 & 1 & 0 & 1 & 1 & 1 & 1 & 1 \\
\hline Stam et al (1984) & 1 & 1 & 1 & 1 & 1 & 0 & 1 & 1 & 1 & 1 & 1 & 0 & 1 & 1 & 0 \\
\hline Spanos et al (1983) & 1 & 1 & 1 & 1 & 0 & 0 & 1 & 1 & 1 & 0 & 1 & 1 & 0 & 1 & 0 \\
\hline Karlin et al (1980) & 0 & 1 & 1 & 1 & 0 & 0 & 1 & 1 & 0 & 0 & 1 & 1 & 1 & 1 & 0 \\
\hline Stam et al (1980) & 1 & 1 & 1 & 0 & 0 & 0 & 1 & 1 & 1 & 1 & 1 & 1 & 1 & 1 & 1 \\
\hline Spanos et al (1980) & 1 & 1 & 1 & 0 & 0 & 0 & 1 & 1 & 1 & 1 & 1 & 1 & 0 & 1 & 0 \\
\hline Wood et al (1976) & 1 & 1 & 0 & 0 & 0 & 0 & 1 & 1 & 1 & 1 & 1 & 0 & 0 & 1 & 0 \\
\hline Li et al (1975) & 0 & 1 & 0 & 1 & 1 & 0 & 0 & 1 & 1 & 1 & 0 & 0 & 1 & 1 & 0 \\
\hline Greene et al (1972) & 1 & 1 & 1 & 0 & 0 & 0 & 1 & 1 & 1 & 1 & 1 & 1 & 0 & 1 & 1 \\
\hline Morgan et al (1970) & 1 & 0 & 0 & 0 & 0 & 0 & 1 & 1 & 0 & 0 & 1 & 1 & 0 & 1 & 0 \\
\hline Evans et al (1970) & 1 & 1 & 1 & 0 & 0 & 0 & 1 & 1 & 1 & 0 & 1 & 0 & 1 & 1 & 0 \\
\hline
\end{tabular}




\begin{tabular}{|c|c|c|c|c|c|c|c|c|c|c|c|c|c|c|c|}
\hline Mean Item Endorsement & 0.95 & 0.79 & 0.64 & 0.34 & 0.18 & 0.25 & 0.92 & 0.96 & 0.71 & 0.59 & 0.82 & 0.73 & 0.67 & 1.00 & 0.42 \\
\hline
\end{tabular}
recruited (e.g. advertisement, course credits, volunteers etc etc); 4-Was there a clear description of the inclusion and exclusion criteria; 5-Were participants assessed to see if they had preexisting pain; 6-Were participants asked to report (or abstain from using) any medication that might affect their experience of pain (e.g. painkilllers); 7-Pain Assessment: Was the method of pain assessment clearly described; 8-Pain Induction: Was the method of pain induction clearly reported; 9-Hypnosis: Was the hypnotic intervention described in adequate detail; 10-Control: Was the control condition described in adequate detail; 11-Was hypnotisability assessed; 12-Comparability of cases and controls; 13-Were relevant participant characteristics adequately described (age, sex etc); 14-Were complete outcome data (i.e., Ms and SDs) available (e.g. reported in article or given via response to data request); 15-Were paticipants randomly allocated to groups (independent-sample designs) or presentation order (repeated-measures designs)? 


\section{PRISMA 2009 Checklist}

\begin{tabular}{|c|c|c|c|}
\hline Section/topic & $\#$ & Checklist item & $\begin{array}{l}\text { Reported } \\
\text { on page \# }\end{array}$ \\
\hline \multicolumn{4}{|l|}{ TITLE } \\
\hline Title & 1 & Identify the report as a systematic review, meta-analysis, or both. & 1 \\
\hline \multicolumn{4}{|l|}{ ABSTRACT } \\
\hline Structured summary & 2 & $\begin{array}{l}\text { Provide a structured summary including, as applicable: background; objectives; data sources; study eligibility criteria, } \\
\text { participants, and interventions; study appraisal and synthesis methods; results; limitations; conclusions and } \\
\text { implications of key findings; systematic review registration number. }\end{array}$ & 2 \\
\hline \multicolumn{4}{|l|}{ INTRODUCTION } \\
\hline Rationale & 3 & Describe the rationale for the review in the context of what is already known. & 3 \\
\hline Objectives & 4 & $\begin{array}{l}\text { Provide an explicit statement of questions being addressed with reference to participants, interventions, comparisons, } \\
\text { outcomes, and study design (PICOS). }\end{array}$ & 4 \\
\hline \multicolumn{4}{|l|}{ METHODS } \\
\hline Protocol and registration & 5 & $\begin{array}{l}\text { Indicate if a review protocol exists, if and where it can be accessed (e.g., Web address), and, if available, provide } \\
\text { registration information including registration number. }\end{array}$ & 5 \\
\hline Eligibility criteria & 6 & $\begin{array}{l}\text { Specify study characteristics (e.g., PICOS, length of follow-up) and report characteristics (e.g., years considered, } \\
\text { language, publication status) used as criteria for eligibility, giving rationale. }\end{array}$ & 5 \\
\hline Information sources & 7 & $\begin{array}{l}\text { Describe all information sources (e.g., databases with dates of coverage, contact with study authors to identify } \\
\text { additional studies) in the search and date last searched. }\end{array}$ & 5 \\
\hline Search & 8 & $\begin{array}{l}\text { Present full electronic search strategy for at least one database, including any limits used, such that it could be } \\
\text { repeated. }\end{array}$ & $\begin{array}{l}\text { Appendix } \\
\text { S1 }\end{array}$ \\
\hline Study selection & 9 & $\begin{array}{l}\text { State the process for selecting studies (i.e., screening, eligibility, included in systematic review, and, if applicable, } \\
\text { included in the meta-analysis). }\end{array}$ & 6 \\
\hline Data collection process & 10 & $\begin{array}{l}\text { Describe method of data extraction from reports (e.g., piloted forms, independently, in duplicate) and any processes } \\
\text { for obtaining and confirming data from investigators. }\end{array}$ & 7 \\
\hline Data items & 11 & $\begin{array}{l}\text { List and define all variables for which data were sought (e.g., PICOS, funding sources) and any assumptions and } \\
\text { simplifications made. }\end{array}$ & 7 \\
\hline $\begin{array}{l}\text { Risk of bias in individual } \\
\text { studies }\end{array}$ & 12 & $\begin{array}{l}\text { Describe methods used for assessing risk of bias of individual studies (including specification of whether this was } \\
\text { done at the study or outcome level), and how this information is to be used in any data synthesis. }\end{array}$ & Table S1 \\
\hline Summary measures & 13 & State the principal summary measures (e.g., risk ratio, difference in means). & 8 \\
\hline Synthesis of results & 14 & $\begin{array}{l}\text { Describe the methods of handling data and combining results of studies, if done, including measures of consistency } \\
\left(e . g ., I^{2}\right) \text { for each meta-analysis. }\end{array}$ & 9 \\
\hline
\end{tabular}




\begin{tabular}{|c|c|c|c|}
\hline Section/topic & \# & Checklist item & $\begin{array}{l}\text { Reported } \\
\text { on page \# }\end{array}$ \\
\hline Risk of bias across studies & 15 & $\begin{array}{l}\text { Specify any assessment of risk of bias that may affect the cumulative evidence (e.g., publication bias, selective } \\
\text { reporting within studies). }\end{array}$ & 10 \\
\hline Additional analyses & 16 & $\begin{array}{l}\text { Describe methods of additional analyses (e.g., sensitivity or subgroup analyses, meta-regression), if done, indicating } \\
\text { which were pre-specified. }\end{array}$ & 9 \\
\hline \multicolumn{4}{|l|}{ RESULTS } \\
\hline Study selection & 17 & $\begin{array}{l}\text { Give numbers of studies screened, assessed for eligibility, and included in the review, with reasons for exclusions at } \\
\text { each stage, ideally with a flow diagram. }\end{array}$ & $\begin{array}{l}10, \\
\text { Fgiure } 1\end{array}$ \\
\hline Study characteristics & 18 & $\begin{array}{l}\text { For each study, present characteristics for which data were extracted (e.g., study size, PICOS, follow-up period) and } \\
\text { provide the citations. }\end{array}$ & $\begin{array}{l}\text { 11, Table } \\
1\end{array}$ \\
\hline Risk of bias within studies & 19 & Present data on risk of bias of each study and, if available, any outcome level assessment (see item 12). & $\begin{array}{c}\text { 12, Table } \\
\text { S1 }\end{array}$ \\
\hline Results of individual studies & 20 & $\begin{array}{l}\text { For all outcomes considered (benefits or harms), present, for each study: (a) simple summary data for each } \\
\text { intervention group (b) effect estimates and confidence intervals, ideally with a forest plot. }\end{array}$ & Figure 2 \\
\hline Synthesis of results & 21 & Present results of each meta-analysis done, including confidence intervals and measures of consistency. & $13-14$ \\
\hline Risk of bias across studies & 22 & Present results of any assessment of risk of bias across studies (see Item 15). & 14 \\
\hline Additional analysis & 23 & Give results of additional analyses, if done (e.g., sensitivity or subgroup analyses, meta-regression [see Item 16]). & 14-15 \\
\hline \multicolumn{4}{|l|}{ DISCUSSION } \\
\hline Summary of evidence & 24 & $\begin{array}{l}\text { Summarize the main findings including the strength of evidence for each main outcome; consider their relevance to } \\
\text { key groups (e.g., healthcare providers, users, and policy makers). }\end{array}$ & 16 \\
\hline Limitations & 25 & $\begin{array}{l}\text { Discuss limitations at study and outcome level (e.g., risk of bias), and at review-level (e.g., incomplete retrieval of } \\
\text { identified research, reporting bias). }\end{array}$ & 19 \\
\hline Conclusions & 26 & Provide a general interpretation of the results in the context of other evidence, and implications for future research. & 17,19 \\
\hline \multicolumn{4}{|l|}{ FUNDING } \\
\hline Funding & 27 & $\begin{array}{l}\text { Describe sources of funding for the systematic review and other support (e.g., supply of data); role of funders for the } \\
\text { systematic review. }\end{array}$ & 20 \\
\hline
\end{tabular}

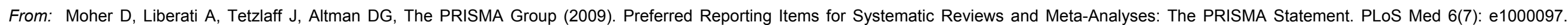
doi:10.1371/journal.pmed1000097 